\title{
New and rare pseudomorphine species from Western Australia (Insecta, Coleoptera, Carabidae, Pseudomorphinae)
}

\author{
Martin Baehr \\ Zoologische Staatssammlung, Münchhausenstr. 21, D-81247 München, \\ Germany. Email: martin.baehrazsm.mwn.de
}

\begin{abstract}
Eight new species of the carabid genera Sphallomorpha Westwood and Adelotopus Hope are described from Western Australia: Sphallomorpha parinterioris, S. permutata, S. szitoi, S. flavorufa, S. clypeosetosa, Adelotopus pilbarae, $A$. basalis and A. minutus. Records from Western Australia of the following rare or poorly documented species are also dealt with: Sphallomorpha froggatti (Macleay), S. fallax (Westwood), S. polysetosa Baehr, S. guttigera (Newman), S. maculata (Newman), S. uniformis Baehr, S. flavopicea Baehr, Adelotopus brevipennis Macleay, A. puncticollis angustemaculatus Baehr, A. rubiginosus Newman, A. houstoni Baehr, A. adustus Baehr, A. coriaceus Baehr, A. paroensis Castelnau, Cainogenion ipsoides occidentale Baehr, and Paussotropus cylindricus (Chaudoir). For Sphallomorpha flavopicea Baehr and Adelotopus houstoni Baehr the male genitalia are described and figured for the first time. All new species and those to which new taxonomic information is added, are inserted in the respective general keys. The Western Australian distributions of most mentioned species are figured in maps.
\end{abstract}

Keywords: taxonomy, new species, Sphallomorpha, Adelotopus, Cainogenion, Paussotropus

\section{INTRODUCTION}

A recent collecting trip through the interior of Western Australia and visits to Western Australian institutions and collections revealed a number of new and rare species of the pseudomorphine genera Sphallomorpha Westwood, Adelotopus Hope, Cainogenion Notman, and Paussotropus Westwood that are described or mentioned in the present paper. During the visit also several common and well documented species were collected or identified (Sphallomorpha castelnaui Reiche, S. hydroporoides Westwood, S. suturalis Germar, Adelotopus laevis Macleay, A. gyrinoides Hope) which are not mentioned further in this paper. For information about these species vide the revisions of the Australian Pseudomorphinae (Baehr 1992, 1997).

In spite of the previous revisions which included almost all material available in collections when they were written, the pseudomorphine fauna of Western Australia, in particular that of the interior, probably is less well known than the faunas of most other parts of Australia. This deficiency may be simply due to the large size of the country which makes reasonable or even systematic sampling of the fauna almost impossible, but also the impression of putative collectors that in a largely dry country with but limited or scattered tree growth pseudomorphine beetles can be rather neglected may be responsible. Fortunately, Western Australian authorities (Western Australian Museum, Department of Conservation and Land Management, Western Australian Department of Agriculture) during the past years conducted a number of surveys in certain parts of Western Australia which revealed, inter alia, a number of interesting pseudomorphine beetles. However, as these beetles can best be sampled mainly by use of specialized methods (pulling down bark into an umbrella, fogging bark), this group certainly is underrepresented in the samples from the previous Goldfields and Wheat Belt surveys and the present Pilbara survey.

The scope of the present paper hence is not only to describe the new species and to make available additional information on species diversity and distribution, but also to draw the attention of collectors to this beetle group and to the arboricolous and corticolous beetle fauna of Western Australia in general, and not only to the beetle fauna but also the very rich fauna of other invertebrates that live on trees, even in the semiarid and arid interior. 


\section{MATERIALS AND METHODS}

Whereas the specimens collected during the ongoing Pilbara survey conducted by the Department of Environment and Conservation, Perth, were sampled by glycol pitfall trapping, the material collected during my travel was either sampled by pulling down sheets of loose bark from a number of bark-shedding eucalypts (Salmon Gum, River Red Gum, Redwood), or by Pyrethrum fogging the rough-barked trunks of a variety of eucalypt and non-eucalypt trees (diverse Mallee, Jarrah, Tuart, Red Tingle, Grevillea, Mulga, and other Acacias).

Dissecting methods and style and format of the descriptions exactly correspond to those in my revisions (Baehr 1992, 1997) and the following supplements (Baehr 1993a, 1993b, 1994b, 2002, 2004, $2005,2006,2007)$ which also can be used to gain additional information about the mentioned genera, their morphology, distribution, and habits. Complete references for previously described species can be taken from the revisions and the supplements and are not included in the literature.

For the benefit of the reader, abbreviations of the chaetotaxy which is particularly important for identification of Sphallomorpha species, are repeated below.

The habitus photographs were obtained with a digital camera using ProgRes Capture Basic and AutoMontage, and were subsequently prepared with Corel Photo Paint 11.

Specimens are lodged in the following institutions: DEC, Department of Environment and Conservation, Woodvale, Western Australia; CBM, working collection of $\mathrm{M}$. Baehr in Zoologische Staatssammlung, München; WADA, Western Australian Department of Agriculture, South Perth; WAM, Western Australian Museum, Perth.

The following abbrevations are used for chaetoatxy:

supraorb, supraorbital seta (either side)

preorb, preorbital seta (either side)

clyp, clypeal seta (either side)

labr, labral setae (common)

ment.med, medial mental setae, at base of mental excision or mental tooth (common)

ment.lat, lateral mental setae, on wings of mentum (either side)

gloss, glossal setae, on ventral rim of apex of glossa (either side)

gul, gular setae, inside of gular suture (either side)

postorb, postorbital setae, posteriorly of eye on a conspicuous rim (either side)

suborb, suborbital setae, below eye, laterally of gular suture (either side)

pron.ant, anterior pronotal setae, near anterior angle of pronotum (either side)

pron.post, posterior pronotal setae, near posterior angle of pronotum (either side) proeps, proepisternal setae, longitudinally and transversally on proepisternum (either side)

marg, marginal setae, along margin of elytra (either side)

st VI, setae on posterior border of sternum VI, the penultimate visible sternite (either side)

$\delta$ st VII, setae of male sternum VII, the terminal visible sternite (either side)

$q$ st VII; setae of female sternum VII, the terminal visible sternite (either side)

\section{SYSTEMATICS}

Family Carabidae Latreille

\section{Subfamily Pseudomorphinae Newman}

Genus Sphallomorpha Westwood, 1837

Sphallomorpha Westwood, 1837: 414; Baehr, 1992: 15.

\section{Type species}

Sphallomorpha decipiens Westwood, 1837, by monotypy.

\section{Remarks}

With about 145 described species this is the largest genus of the subfamily Pseudomorphinae and, with respect to the great number of plesiomorphic character states, it is the most basal genus and altogether the adelphotaxon of all other genera (Baehr 1994a). It's basal status is also demonstrated by the ovipary of all species, whereas all other genera of Pseudomorphinae (except Cryptocephalomorpha the reproduction mode of which is still unknown) are ovoviviparous. The overwhelming majority of the species occur in Australia, with a few species recorded from New Guinea. In Australia, species of Sphallomorpha occur in most environments, provided some tree growth is present, because the species generally occur on trees and prefer bark-shedding eucalypts, where during daytime they hide under the bark. Several species have been recorded from rainforest ecosystems, but the majority occur in open forest and even in rather dry country.

\section{Sphallomorpha froggatti (Macleay, 1888)}

Silphomorpha froggatti Macleay, 1888: 457; Sphallomorpha froggatti, Baehr, 1992: 63; Baehr, 2002: 102.

\section{New material examined}

Australia: Western Australia: 1 b, site WA06/ 134, $2 \mathrm{~km} \mathrm{~S}$. of crossing of Tom Price Road and Paraburdoo Road, $22.95025^{\circ} \mathrm{S}, 117.34708^{\circ} \mathrm{E}, 396 \mathrm{~m}$, 17 February 2006, M. Baehr (WAM 67920). 


\section{Remarks}

The new specimen is the first recent record of $S$. froggattifrom Western Australia south of the Great Sandy Desert. This common species was previously known from north-eastern Queensland from about Rockhampton through northern tropical Northern Territory to the Kimberley Division in northernmost Western Australia.

The single specimen was fogged from the rough bark on the trunk of a Mulga Acacia (Acacia aneura).

\section{Sphallomorpha fallax (Westwood, 1837)}

Figure 16

Silphomorpha fallax Westwood, 1837: 426.

Sphallomorpha fallax (Westwood): Baehr, 1992: 79;

Baehr, 2002: 102.

\section{New material examined}

Australia: Western Australia: 1 o, site WA06/25, $20 \mathrm{~km} \mathrm{~N}$. of Widgemooltha, 31.35341\% $121.51929^{\circ} \mathrm{E}, 355 \mathrm{~m}, 5$ January 2006, M. Baehr (CBM); 1 s, site WA06/20, $46 \mathrm{~km} \mathrm{NE.} \mathrm{of} \mathrm{Peak}$ Charles, $32.64199^{\circ} \mathrm{S}, 121.50504 \mathrm{E}, 237 \mathrm{~m}, 27$ January 2006, M. Baehr (CBM).

\section{Remarks}

These are the first recent records which corroborate the occurrence of this common eastern species in Western Australia. Baehr (1992: 83) reported only a few very old, imprecisely labelled specimens from Western Australia. At both locations specimens were sampled from under bark of Salmon Gums (Eucalyptus salmonophloia) or similar eucalypts.

\section{Sphallomorpha parinterioris sp. nov.} Figures 1, 16

Sphallomorpha interioris Baehr, 1992: 94 (in part).

\section{Material examined}

\section{Holotype}

Australia: Western Australia: 8 , site WA06/157 $90 \mathrm{~km} \mathrm{~W}$. of Sandstone, $28.05690^{\circ} \mathrm{S}, 118.44989^{\circ} \mathrm{E}$ 444 m, 27 February 2006, M. Baehr (WAM 67921).

\section{Paratypes}

Australia: Western Australia: 2,1 , same data (CBM, I WAM 67922); 1 d, site WA06/156, $35 \mathrm{~km}$ N. of Mount Magnet, 27.81594 S, 117.92478 E, 422 m, 27 February 2006, M. Baehr (CBM); 1 , site WA $26,38 \mathrm{~km}$ SSE of Leinster, 7-8 November 1987, M. Baehr (CBM; also paratype of Sphallomorpha interioris); 1 \&. Wooramel River, 2547' $11558 \mathrm{E}$, 14 April 1979, M. Peterson (WAM 87/2176; also paratype of Sphallomorpha interioris).

\section{Etymology}

The name refers to the close relationship of this species to Sphallomorpha interioris Baehr from central Northern Territory.

\section{Diagnosis}

A species of the mastersii species-group (Baehr 1992) with coarsely punctate elytral striae and fairly coarse punctations of intervals, and with slightly bent-down apex of the aedeagus. Distinguished from the most similar $S$. interioris Baehr by the more asymmetrical shape and less distinctly bent apex of aedeagus, and the elongate female stylomere 2.

\section{Description}

Measurements: length: 12.6-13.7 mm; width: $6.7-$ $7.2 \mathrm{~mm}$. Ratios: width pronotum/head: 1.60-1.69; width elytra/pronotum: $1.07-1.11$; width/length of pronotum: 2.33-2.50; length/width of elytra; $1.20-$ 1.25; length elytra/pronotum: $3.16-3.40$.

Colour: black, mouth parts and lateral margins of pronotum and elytra more or less distinctly reddish-piceous, apex of palpi light reddish. Antenna reddish. Lower surface dark piceous to black, metathorax and abdomen slightly lighter. Legs including femora reddish-piceous to piceous.

Chaetotaxy (Figures 1A-C): supraorb: 1; preorb:-, clyp: 1; labr: 4; ment.med: 2 ; ment.lat: 5-6; gloss: 4 ; gul: 2; postorb: 3-4; suborb: 6-8; pron.ant: 1; pron post: 1; proeps: $1-2+5-6$; marg: 16-18; st VI: 2; 3 st VII: $2-3$; 9 st VII: $3-4$.

Head (Figure 1A): wide, rather depressed, frontal impressions large, shallow. Eyes large, very convex. Clypeus feebly concave, clypeal sutures distinct, elongate. Lateral border of head anteriorly very oblique, almost straight, then convex, markedly incurved towards eyes. Labrum wide, short, laterally convex, medially moderately excised. Wings of mentum short, apex wide, evenly rounded, subapically feebly concave, then convex, medially obliquely convex. Glossa slightly excised, not or feebly excavate, border obtuse, 4-setose. Dorsal part much surpassing ventral, medially feebly excised, without hairs or bristles. Terminal palpomere of labial palpus elongate, with very oblique apex, rather securiform, of maxillary palpus elongate, not securiform. Median antennomeres c. 5 $x$ as long as wide. Microreticulation very dense and fine, distinct, slightly rugose, punctuation almost invisible, surface with some transverse strioles laterally of clypeal sutures, with variably distinct strioles medially of eves and on frons, and with very fine and sparse erect pilosity, dull. Palpi very indistinctly pilose. Galea with few short hairs only at apex. Ventral surface with very few, short hairs or almost glabrous.

Pronotum: wide, fairly depressed, laterally explanate. Apex fairly narrow, with rather shallow, 

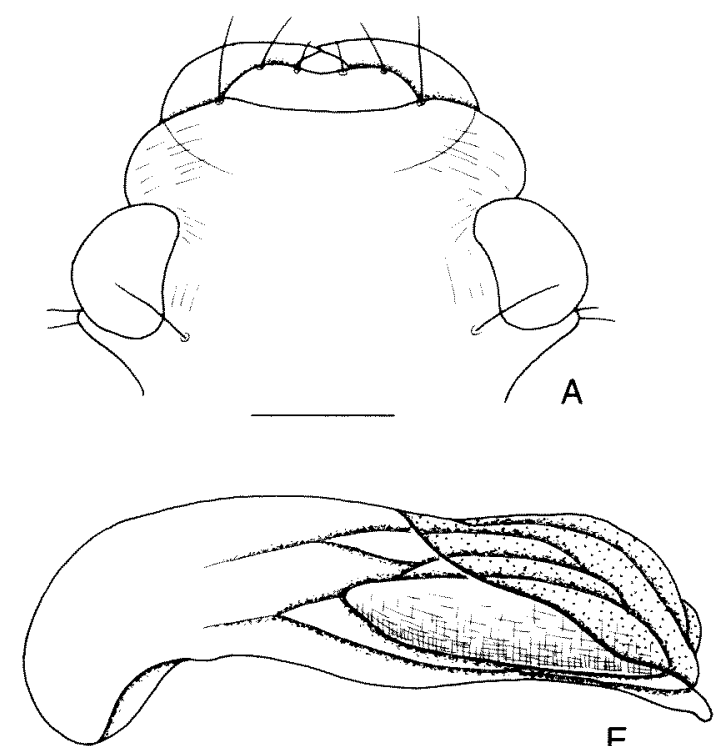

E

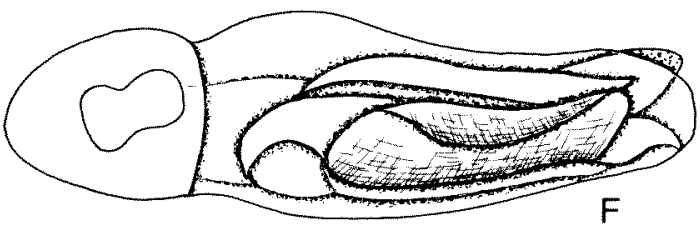

$\mathrm{F}$

G

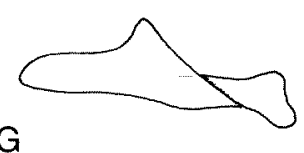

Figure 1

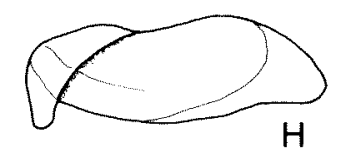

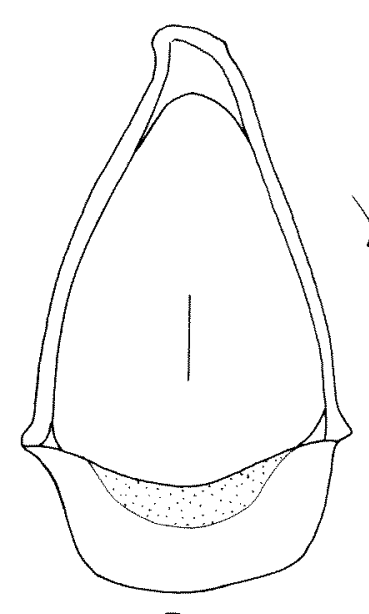
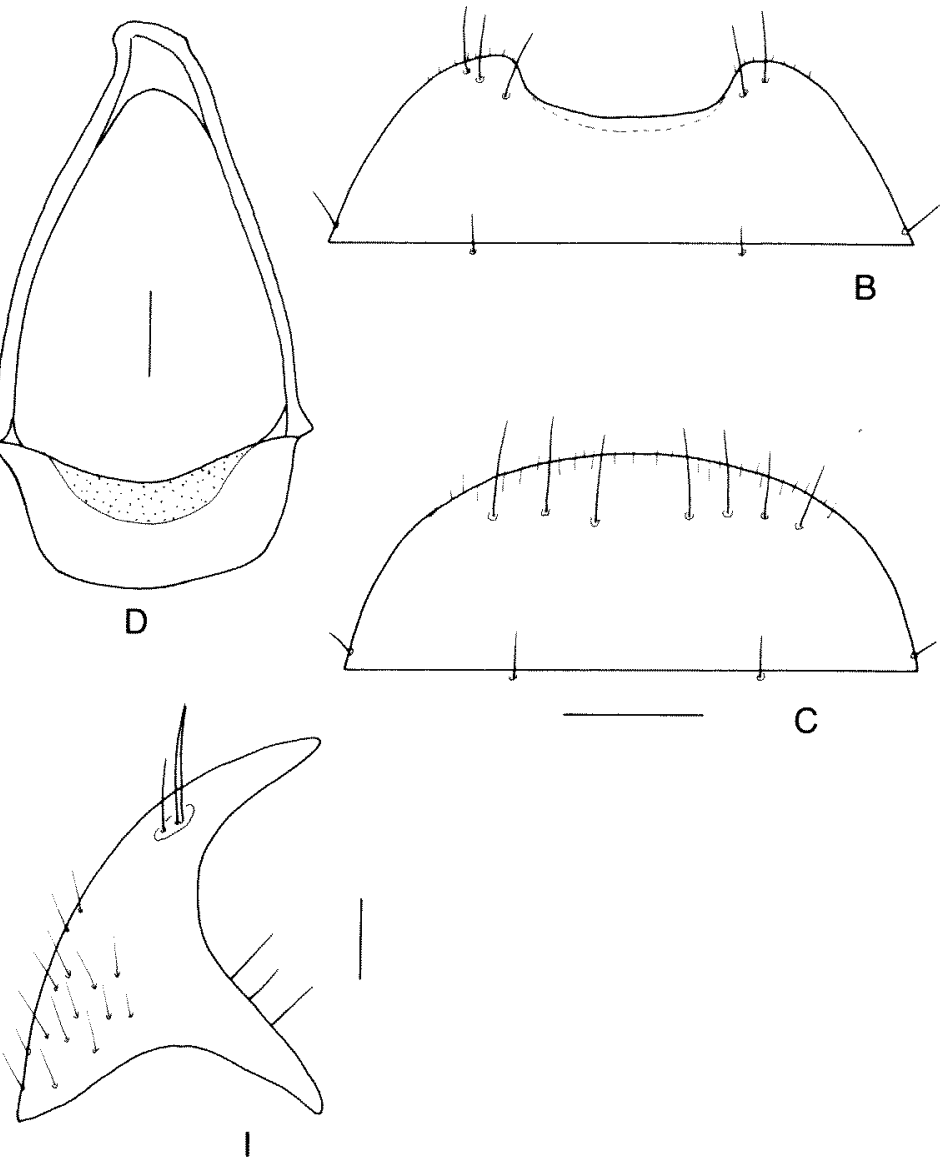

C

Sphallomorpha parinterioris, sp. nov, details of head and genitalia. A, dorsal surface of head; B, male sternum VII; C, female sternum VII; D, male genital ring; E, lateral view of aedeagus; F, lower surface of aedeagus; $G$, right paramere; $H$, left paramere; $I$, female stylomere 2. Scale lines: $A-C(1 \mathrm{~mm})$; $-H(0.5 \mathrm{~mm})$; I $(0.1 \mathrm{~mm})$.

medially slightly convex excision. Anterior angles short, very wide, apex barely obtuse. Sides evenly convex, widest at posterior third, far in front of posterior marginal seta. Base gently bisinuate. Lateral margins with extremely fine border line. Discal impressions irregular, very shallow, or almost invisible. Microreticulation very fine, dense, distinct, punctuation very fine, sometimes virtually invisible, surface with dense network of fine, irregular strioles, giving the surface a rather coriaceous appearance, and with extremely fine, sparse, erect pilosity, dull.

Elytra: elongate, fairly depressed, laterally almost parallel. Apex wide, slightly oblique, almost straight. Striae more or less well impressed, marked by rows of fairly coarse punctures, intervals feebly raised. Series of marginal punctures slightly interrupted in middle. Microreticulation fine and dense, rather distinct and slightly rugose, punctuation moderately coarse, irregular, fairly dense, surface with extremely sparse, fine pilosity, difficult to detect, rather dull.

Lower surface: prosternal process moderately elongate, fairly wide, apex rounded, lower surface convex, moderately curved to apex, apex with 2 elongate setae, lower surface with some very short hairs; metepisternum c. 2.2.-2.3 $\mathrm{x}$ as long as wide.

Legs: very elongate. Metatarsus slightly longer than metatibia. At least basal tarsomeres slightly pilose on upper surface. $1^{\text {st }}$ tarsomere of metatarsus about as long as $2^{\text {nd }}$ and $3^{\text {rd }}$ tarsomeres together.

Male genitalia (Figures 1B, D-H): sternum VII wide, triangular, with very wide, shallow, rectangular excision. Genital ring moderately wide, basal border convex, lateral angles evenly rounded, lateral borders oblique, basal plate moderately short, anteriorly deeply excised, arms almost symmetrical. Aedeagus straight on upper, bisinuate on lower surface, left side characteristically sinuate; apex very wide, obtuse, very gently bent down. Orifice elongate. Internal sac large, inconspicuously microtrichiate, with elongate fold, for pattern see Figures 1E, F. Right paramere shallow, apex elongate, rather narrow, lower surface gently sinuate. Left paramere elongate, shallow, conspicuously sinuate on both, 
upper and lower borders, with tapering, rouded apex.

Female genitalia (Figures 1C, I): sternum VII moderately elongate, border rather convex, with several short hairs along and near margin. Stylomere 2 small though elongate, with acute, elongate apex. Des and ves absent. Usually with 3 ns. Pilosity dense.

Variation: very little variation is apparent in the size, body proportions and colour, and all specimens lack the preorbital seta. They very slightly differ from both specimens from Western Australia which previously were included in $S$. interioris.

\section{Distribution}

Central Western Australia (Figure 16).

\section{Habits}

The habits of this species are largely unknown. The newly recorded specimens were fogged from the rough bark of the trunks of Mulga Acacias (Acacia aneura). The specimen from near Leinster originally identified as Sphallomorpha interioris was sampled from under bark of an unidentified eucalypt.

\section{Remarks}

A striking variation in the female stylomeres was noted in the description of Sphallomorpha interioris by Baehr (1992). Because only the holotype from Yuendumu (Northern Territory) was a male, nothing could then be said about any variation in the male genitalia. The newly discovered males from interior Western Australia now reveal a slightly different aedeagus and, moreover, in the single female the stylomeres are of similarly elongate shape as those of the females from Western Australia previously ascribed to $S$. interioris. Therefore, the Western Australian specimens are described as a new species and both Western Australian female paratypes of $S$. interioris are transferred to this new species.

According to the chaetotaxy of the labrum, shape of the terminal male sternum, and chaetotaxy of female stylomeres, this species belongs to the mastersii species-group in the sense of Baehr (1992) and is most closely related to $S$. interioris Baehr from central Northern Territory.

\section{Sphallomorpha polysetosa Baehr, 1992 Figure 16}

Sphallomorpha polysetosa Baehr, 1992: 97.

\section{New material examined}

Australia: Western Australia: 2 , site WA06/36, $3 \mathrm{~km} \mathrm{NW}$. of Bullfinch, $30.98853^{\circ} \mathrm{S}, 119.10307^{\circ} \mathrm{E}, 342$ m, 8 January 2006, M. Baehr (CBM).

\section{Remarks}

This is a a rare species of which only three female specimens from south-Western Australia and South Australia have been recorded (Baehr, 1992). Because the only known specimens of $S$. polysetosa are females, the exact taxonomic position of this species will remain unknown. Both specimens were collected from under bark of Redwood (Eucalyptus transcontinentalis).

\section{Sphallomorpha permutata sp. nov.} Figures 2, 11, 17

\section{Material examined}

\section{Holotype}

Australia: Western Australia: ơ, site WA06/25, $20 \mathrm{~km} \mathrm{~N}$. of Widgemooltha, $31.35341^{\circ} \mathrm{S}$, $121.51929^{\circ} \mathrm{E}, 355 \mathrm{~m}$, 5 January 2006, M. Baehr (WAM 67923).

\section{Paratypes}

Australia: Western Australia: $3 \delta, 1 \uparrow$, same data (CBM, 1 WAM 67924); 2 o, site WA06/26, $5 \mathrm{~km} \mathrm{E.}$ of Bulla Bulong, $30.76968^{\circ} \mathrm{S}, 121.79970^{\circ} \mathrm{E}, 376 \mathrm{~m}, 6$ February 2006, M. Baehr (CBM); 1 q, site WA06/18, Peak Charles National Park at base of Peak Charles, $32.88300^{\circ} \mathrm{S}, 121.16929^{\circ} \mathrm{E}, 295 \mathrm{~m}, 3$ January $2006, \mathrm{M}$. Baehr (CBM); 1 , site WA06/31, Boondi Rock, Goldfields National Park, $31.18300^{\circ} \mathrm{S}, 120.38293^{\circ} \mathrm{E}$, 428 m, 6 January 2006, M. Baehr (CBM).

\section{Etymology}

Latin "permutata" means "easily confused" and refers to the very high level of similarity with the eastern S. polita (Macleay).

\section{Diagnosis}

This is a species of the laevis species-group (Baehr 1992) and, due to the body shape and chaetotaxy, most similar to S. polita (Macleay) from eastern Australia. It is distinguished from that species by the greater number of abdominal stemal setae in both sexes, the slightly more asymmetrical aedeagus, the smaller and much less conspicuous dark, sclerotized area on the left side of the internal sac, and the longer and narrower left paramere.

\section{Description}

Measurements: length: 9.9-10.8 mm; width: 5.3$5.9 \mathrm{~mm}$. Ratios: width pronotum/head: 1.68-1.74; width elytra/pronotum: 1.07-1.09; width/length of pronotum: 2.50-2.57; length/width of elytra; 1.15 1.18; length elytra/pronotum: 3.16-3.25.

Colour: very dark piceous to black, lateral margins of pronotum and elytra very inconspicuously lighter. Labrum and mouth parts reddish, antenna light reddish. Ventral surface light 


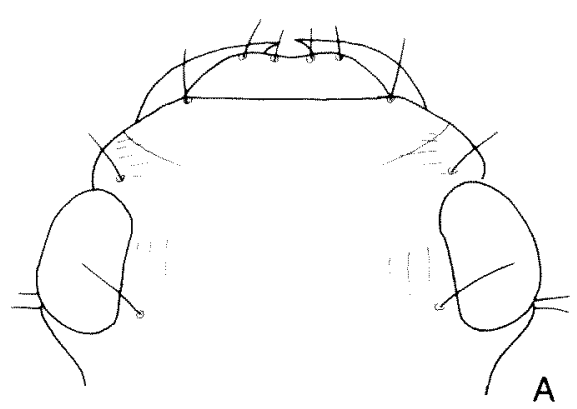

A

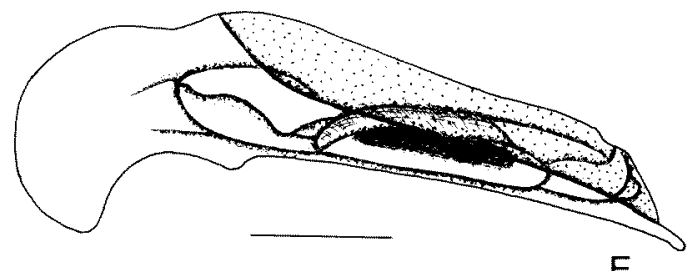

E

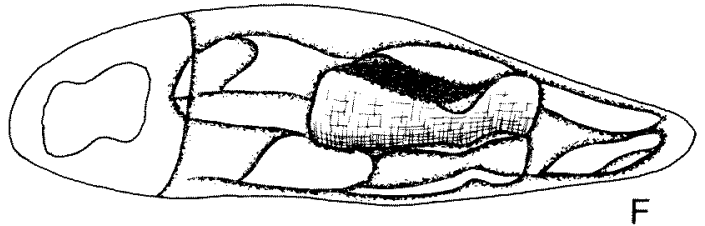

$F$

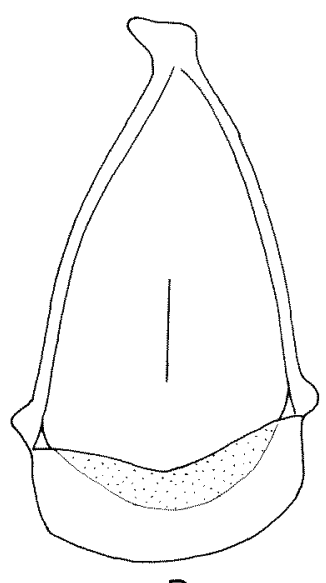

D

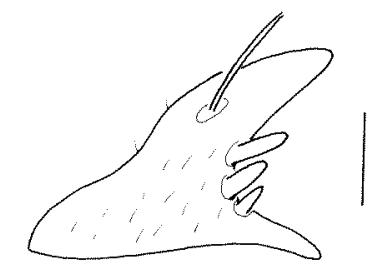

I
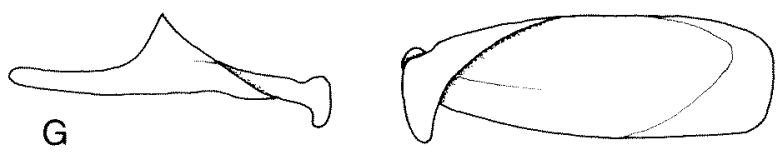

Figure 2 Sphallomorpha permutata, sp. nov., details of head and genitalia: A, dorsal surface of head; B, male sternum VII; C, female sternum VII; D, male genital ring; E, lateral view of aedeagus; F, lower surface of aedeagus; G, right paramere; $\mathrm{H}$, left paramere; $\mathrm{I}$, female stylomere 2 . Scale lines: A-C $(1 \mathrm{~mm})$; D-H $(0.5 \mathrm{~mm})$; $(0.1 \mathrm{~mm})$.

reddish, head reddish-piceous, laterally slightly darker, centre of abdomen reddish. Legs dark reddish, femora slightly lighter.

Chaetotaxy (Figures 2A-C): supraorb: 1; preorb: 1, clyp: 1; labr: 4; ment.med: -; ment.lat: 5-6; gloss: 4; gul: 1 ; postorb: $3-4$; suborb: 7-9; pron.ant: 1 ; pron.post: 1; proeps: $1-2+4-5$; marg: 19-20; st VI: 3-4; oे st VII: $17-18$; क st VII: 19-20.

Head (Figure 2A): moderately wide, fairly depressed, frontal impressions almost absent. Clypeus barely concave, clypeal sutures moderately distinct, elongate. Lateral border of head oblique, posteriorly gently convex, slightly incurved in front of eyes. Labrum wide, laterally obliquely convex, anteriorly feebly excised, barely raised. Mentum with very shallow, wide, medially straight or convex prominence. Wings of mentum short, wide, apex evenly rounded, subapically more or less convex, medially obliquely convex. Glossa gently excised, slightly excavate, border moderately obtuse. Dorsal part not much surpassing ventral, excised in middle, with few delicate hairs. Terminal palpomere of labial palpus fairly elongate, with very oblique apex, slightly securiform, of maxillary palpus rather elongate, with feebly convex borders and very oblique apex, barely securiform. Median antennomeres c. $3 \times$ as long as wide. Microreticulation dense and rather fine, fairly coarse, punctuation dense, moderately fine, more or less easily visible, surface with some transverse strioles laterally of clypeal sutures, with variously developed, fine, irregular strioles on frons, and with very short, erect pilosity, moderately dull. Palpi with fairly hirsute pilosity. Galea with some short hairs along anterior border and at apex. Ventral surface almost impilose.

Pronotum: moderately wide, fairly depressed, laterally barely explanate. Apex wide, with moderately deep excision. Anterior angles moderately projecting, apex feebly obtuse. Sides moderately, though evenly convex, widest slightly in front of posterior marginal seta. Base gently concave or bisinuate. Lateral margin anteriorly with distinct, posteriorly with feeble border line. Discal impressions very shallow, irregular. Microreticulation dense, rather fine, distinct, punctuation fairly dense, rather fine, sometimes inconspicuous, surface with more or less distinct network of fine, 
irregular strioles, and with very fine, moderately dense, erect pilosity, rather dull.

Elytra: rather elongate, fairly convex, laterally barely explanate, feebly rounded to almost parallel. Apex wide, obliquely rounded. Striae barely impressed, but marked by rows of moderately fine punctures. Intervals very gently raised or almost depressed. Series of marginal pores slightly spaced in middle. Microreticulation dense and distinct, punctuation fine though conspicuous, dense, sometimes less distinct within microreticulation. Surface with delicate, rather sparse pilosity, difficult to see, rather dull to somewhat glossy, depending on degree of microreticulation and of puncturation.

Lower surface: prosternal process fairly short, rather narrow, attenuate, apex almost straight, ventral surface convex, more or less curved to apex, with several short hairs. Metepisternum c. $1.8 \mathrm{x}$ as long as wide.

Legs: rather elongate. Metatarsus almost as long as metatibia. $1^{\text {st }}$ tarsomere of metatarsus as long as $2^{\text {nd }}$ and $3^{\text {rd }}$ tarsomeres together.

Male genitalia (Figures 2B, D-H): sternum VII moderately wide, with fairly wide, deep excision and many very elongate setae. Genital ring moderately wide, triangular, basal border gently convex, lateral angles rounded, lateral borders not sinuate, basal plate short and wide, anteriorly moderately, triangularly excised, arms gently convex. Aedeagus rather short and stout, lower surface almost straight, lateral margins attenuate though left side very gently excised. Apex moderately obtuse, very feebly curved down. Orifice very elongate. Internal sac in parts markedly microtrichiate, on left side with conspicuous, dark area, for pattern see Figures 2E, F. Right paramere narrow and very elongate, straight, apex elongate, parallel. Left paramere very elongate, almost parallel, with almost transversal apical border.

Female genitalia (Figures 2C, I): sternum VII fairly wide and short, apical border almost straight, with many very elongate setae arranged in 2 rows, and with several short hairs along border. Stylomere 2 short, with short, wide, fairly obtuse apex, with 3 ves of decreasing size, and 2 ns. Pilosity rather sparse.

Variation: very little variation noted.

\section{Distribution}

This species is restricted to interior southern Western Australia (Figure 17).

\section{Habits}

Most specimens of this species were sampled from under bark of Salmon Gums (Eucalyptus salmonophloia), the specimen from Peak Charles was collected from under bark of an unidentified Mallee eucalypt, that from Boondi Rock was sampled at black light at the margin of a dry salt lagoon surrounded by eucalypt forest.

\section{Remarks}

In body shape, structure of surface, chactotaxy, and structure of aedeagus, this species is extremely similar to the common eastern species $S$. polita which ranges from south-eastern New South Wales through Australian Capital Territory to northeastern Queensland. The best characters to distinguish between both species are the abdominal chaetotaxy, the shape of the aedeagus, and the structure of the internal sac.

According to the structure of the lower surface of the head, the chaetotaxy of the labrum, the shape of the male aedeagus, and the structure of the female stylomeres, this species belongs to the laevis species-group (Baehr, 1992) and according to the great number of abdominal setae it is most similar to S. polita from eastern Australia.

\section{Sphallomorpha szitoi sp. nov.}

Figures 3, 17

\section{Material examined}

\section{Holotype}

Australia: Western Australia: 9, $40 \mathrm{~km} \mathrm{N.} \mathrm{of}$ Badgingarra, UV light, 1-15 March 1995, A. Szitó (WADA 27442).

\section{Etymology}

The name honours the collector and curator of the Western Australian Department of Agriculture Insect Collection, Dr. A. Szitó.

\section{Diagnosis}

This is probably a species of the semistriata species-group (Baehr 1992). In view of absence of striation of the elytra, and of the sparse chaetotaxy of the terminal abdominal sternite, it is probably most similar to S. parallela Baehr. It is distinguished from that species by its larger size, much denser punctuation of the pronotum and elytra, and the very low number of abdominal sternal setae.

\section{Description}

Measurements: length: $8.7 \mathrm{~mm}$; width: $4.6 \mathrm{~mm}$. Ratios: width pronotum/head: 1.73 ; width elytra/ pronotum: 1.09 width/length of pronotum: 2.50 ; length/width of elytra; 1.26; length elytra/ pronotum: 3.41

Colour: very dark piceous, almost black, pronotum and elytra laterally very slightly translucent. Labrum and mouth parts reddish-piceous, antenna dirty yellow. Lower surface dark yellow, head, especially lateral parts, and centre of abdomen darker. Legs light reddish, femora dirty yellow. 

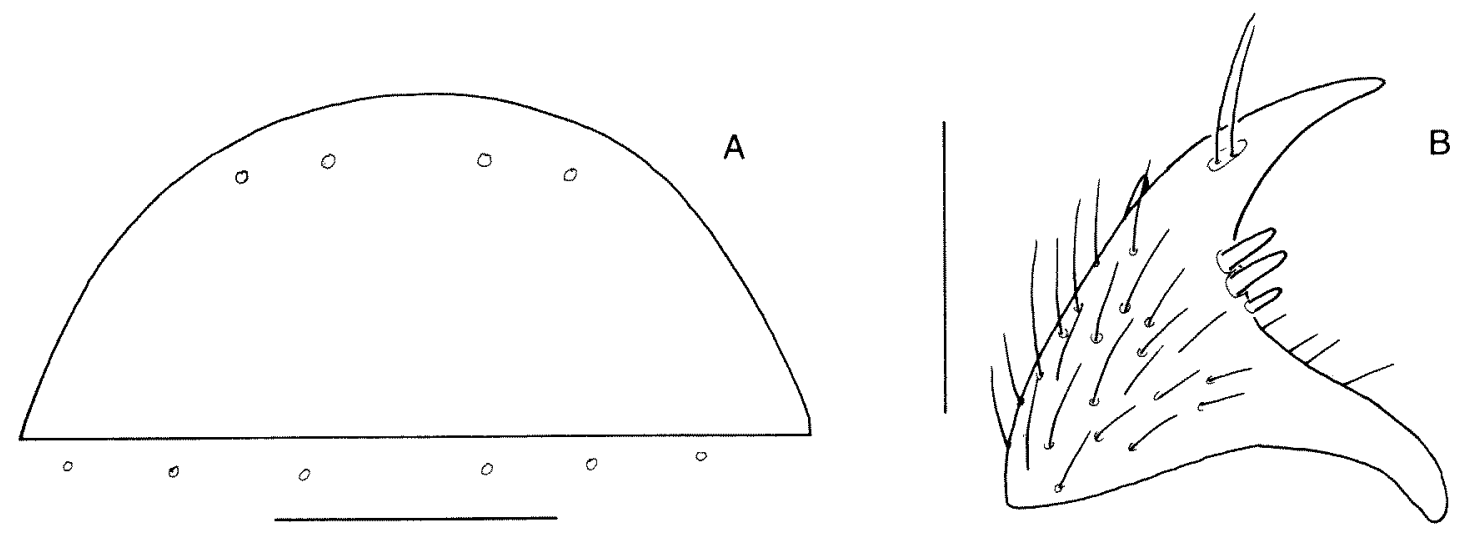

Figure 3 Sphallomorpha szitoi sp. nov., details of female genitalia: A, female sternum VII; B, female stylomere 2. Scale lines: A $(1 \mathrm{~mm})$; B $(0.2 \mathrm{~mm})$.

Chaetotaxy (Figure 3A): supraorb: 1; preorb: 1, clyp: 1; labr: 4; ment.med: -; ment.lat: 1; gloss: 3-4; gul: 2 ; postorb: 3 ; suborb: $3-4$; pron.ant: 1 ; pron.post: -; proeps: $1+3-4$; marg: 14-15; st VI: 3 ; $\delta$ st VII: ?; q st VII: 2.

Head: rather wide and short, without distinct frontal impressions. Eyes large, moderately projecting. Clypeus feebly concave, clypeal sutures fairly distinct, elongate. Lateral borders of head oblique, slightly convex, incurved in front of eyes. Labrum rather wide, anteriorly widely, moderately deeply excised, barely raised. Gular sutures rectangular, though angle rather obtuse. Mentum with very shallow prominence. Wings of mentum short, wide, apex evenly rounded, subapically feebly convex, medially little oblique. Glossa faintly excised, slightly excavate, border rather obtuse. Dorsal part little surpassing ventral, medially deeply excised, with several distinct short hairs. Terminal palpomere of labial palpus elongate, narrow, not securiform, of labial palpus elongate, parallel. Galea rather narrow, little widened. Antenna probably fairly elongate, but both antennae broken from $4^{\text {th }}$ antennomere. Microreticulation dense, distinct, punctuation barely visible, surface with few inconspicuous, transverse strioles laterally of clypeal sutures and with very short, sparse, erect pilosity, dull. Palpi rather densely pilose. Ventral surface with scattered, short pilosity.

Pronotum: fairly wide, rather depressed, laterally barely explanate. Apex with fairly deep, medially slightly convex excision. Anterior angles moderately acute, apex feebly obtuse. Sides evenly convex, widest slightly in front of posterior marginal setae. Posterior border shortly rounded. Base almost straight. Lateral margin with distinct border line. Discal impressions faint. Microreticulation dense, distinct, punctuation fine, rather sparse, surface with some irregular strioles, and with very fine, sparse, erect pilosity, rather dull.
Elytra: elongate, moderately depressed, laterally very little rounded, almost parallel, laterally not explanate. Apex very wide, very oblique, straight. Striae not impressed, only three inner striae in basal half marked by irregular rows of slightly more coarse punctures. Intervals absolutely not raised. Series of marginal pores in middle well spaced. Microreticulation distinct, though somewhat superficial, punctuaation fine though dense distinct, surface with very fine, sparse, erect pilosity, rather glossy.

Lower surface: prosternal process moderately elongate, narrow, apex rounded, ventral surface rather depressed, evenly curved to apex, with few elongate setae at apex and with some short hairs. Metepisternum slightly less than twice as long as wide.

Legs: rather elongate. Metatarsus broken on both legs.

Male genitalia: unknown.

Female genitalia (Figures 3A, B): sternum VII very elongate, apical border remarkably convex, with 2 setae on either side, but setae broken. Stylomere 2 comparatively elongate, with narrow, elongate, very acute apex, with 3 ves of decreasing size, one des and 2 ns. Pilosity dense and elongate.

Variation: unknown.

\section{Distribution}

This species has only been found at the type locality in south-western Australia (Figure 17).

\section{Habits}

The habits of this species are largely unknown. The holotype was collected at light. Nevertheless, this is certainly a bark-inhabiting species like its congeners.

\section{Relationships}

According to the structure of the lower surface of 
the head, the chaetotaxy of labrum, the chaetotaxy of the female sternum, and the structure of the female stylomeres, this species most probably belongs to the semistriata species-group (Baehr, 1992). According to the very small number of abdominal setae it resembles $S$. parallela Baehr from south-Western Australia.

\section{Sphallomorpha guttigera (Newman, 1842)}

Silphomorpha guttigera Newman, 1842: 367.

Sphallomorpha guttigera (Newman): Baehr, 1992: 207.

\section{New material examined}

Australia: Western Australia: $1 \delta$, Kellerberrin, W. Crawshaw (WADA).

\section{Remarks}

This species ranges from eastern South Australia through Victoria, Australian Capital Territory to northern New South Wales (Baehr, 1992). The new record from south-western Western Australia thus is doubtful, in particular because it is rather old, and it should be corroborated with new material. For the present, and because the whole guttigera species-group in the sense of Baehr $(1992,1994 b)$ so far is unknown from Western Australia, the occurrence of $S$. guttigera in Western Australia is highly doubtful.

\section{Sphallomorpha maculata (Newman, 1842)} Figure 16

Silphomorpha maculata Newman, 1842: 365

Sphallomorpha maculate (Newman): Baehr, 1992: 235; Baehr, 2002: 107.

\section{New material examined}

Australia: Western Australia: 1 b, site WA06/ 141, $15 \mathrm{~km} \mathrm{SE}$. of Florence Homestead, 21.90256 ${ }^{\circ}$, $118.00259^{\circ} \mathrm{E}, 297 \mathrm{~m}, 21$ February 2006, M. Baehr (CBM).

\section{Remarks}

This species is currently known from scattered localities in eastern South Australia, Victoria, Australian Capital Territory, New South Wales, and southern Queensland (Baehr, 1992, 2002), although most records, in particular all from South Australia, are old and mostly without precise localities. The specimen mentioned above hence is the first record from Western Australia and demonstrates the wide distribution of this rare inland species. The specimen was fogged from the trunk of an unidentified, very rough-barked eucalypt.

\section{Sphallomorpha uniformis Baehr, 1992}

Figure 16

Sphallomorpha uniformis Baehr, 1992: 261.

\section{New material examined}

Australia: Western Australia: 1 , site WA06/56, Wooramel River near Meedo Homestead, $25.65391^{\circ} \mathrm{S}, 114.62463^{\circ} \mathrm{E}, 70 \mathrm{~m}, 14$ January $2006, \mathrm{M}$ Baehr (CBM).

\section{Remarks}

Sphallomorpha uniformis is a widespread species of the interior of Australia, recorded from central Queensland west of the Great Dividing Range, central Northern Territory, and Western Australia south of the Great Sandy Desert. The new specimen was captured from under bark of a River Red Gum (Eucalyptus camaldulensis) on the banks of the dry Wooramel River.

\section{Sphallomorpha flavopicea Baehr, 1992}

Figures 4, 18

Sphallomorpha flavopicea Baehr, 1992: 263.

\section{New material examined}

Australia: Western Australia: 2 o, site WA06/76, Koorarawalyee, $30 \mathrm{~km}$ E. of Yellowdine, $31.25878^{\circ} \mathrm{S}$, $120.01429^{\circ} \mathrm{E}, 433 \mathrm{~m}, 25$ January 2006, M. Baehr (CMB); 1 o, site WA06/72, $28 \mathrm{~km}$ SSW. of Koolyanabbin, $31.02773^{\circ} \mathrm{S}, 119.44876^{\circ} \mathrm{E}, 348 \mathrm{~m}, 24$ January 2006, M. Baehr (CMB); $1 \delta, 60$ miles S. of Halls Creek, 6 December 1971, D. Williams, N.S. Expedition IV (WAM 45086).

\section{Description}

Male

Chaetotaxy (Figure 4A). of st VII: 3.

Male genitalia (Figures $4 \mathrm{~A}-\mathrm{F}$ ). Sternum VII rather narrow and elongate, with deep, about $v$-shaped excision. Genital ring narrow, elongate, basally rather convex, lateral angles slightly prominent, though rounded, basal plate elongate, anteriorly barely excised, arms almost straight. Aedeagus elongate, fairly narrow, symmetrical, apex elongate, acute, gently upturned. Lower left surface conspicuously knobbed. Orifice moderately elongate. Internal sac conspicuously microtrichiate, for pattern see Figures $4 B, C$. Apex of right paramere moderately elongate. Left paramere elongate, narrow, upper border slmost straight, lower border gently convex near base, apex obliquely convex.

\section{Remarks}

Sphallomorpha flavopicea is a rare species, hitherto known from only three female specimens, all from the southern part of Western Australia. In 

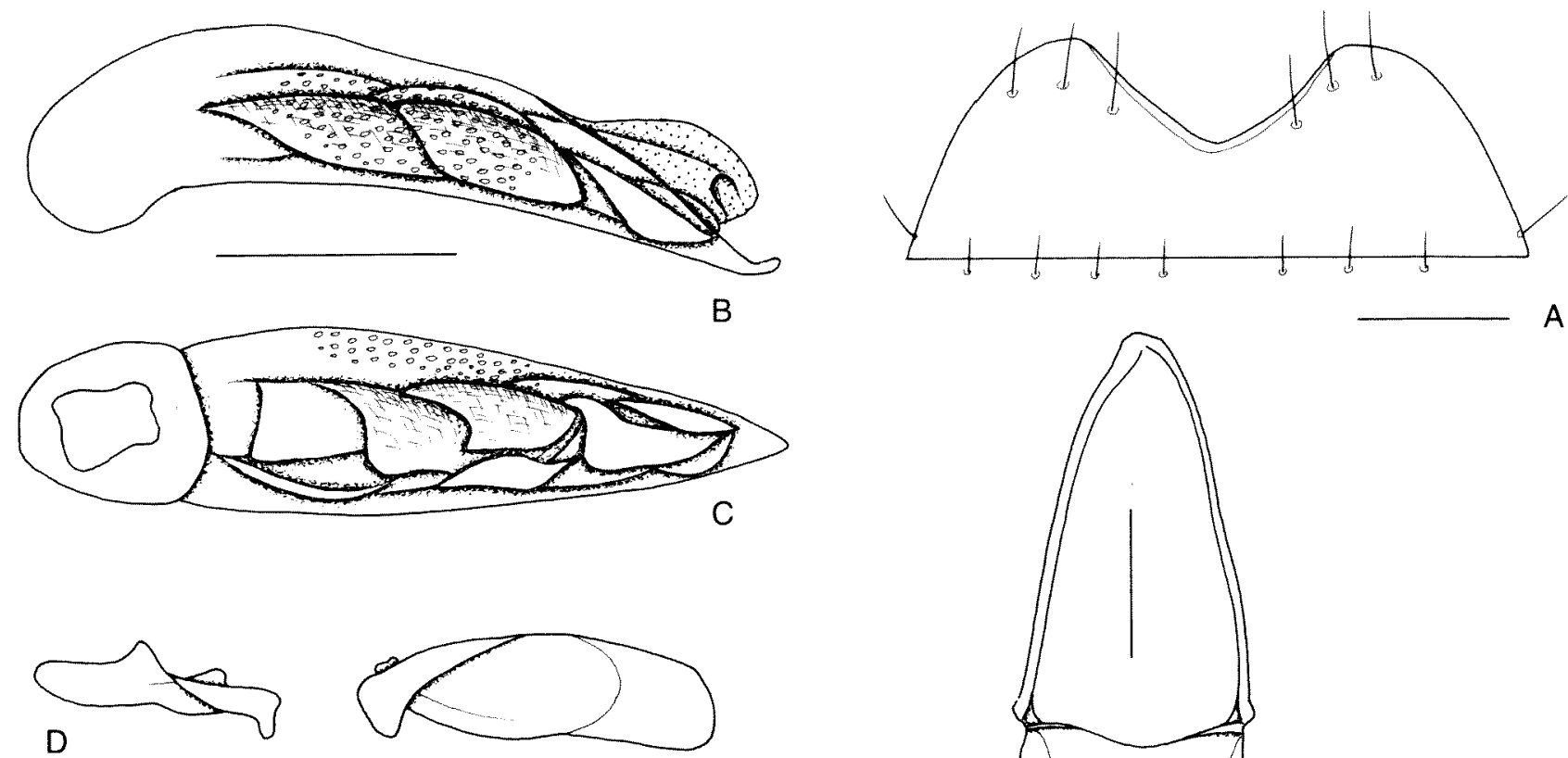

B

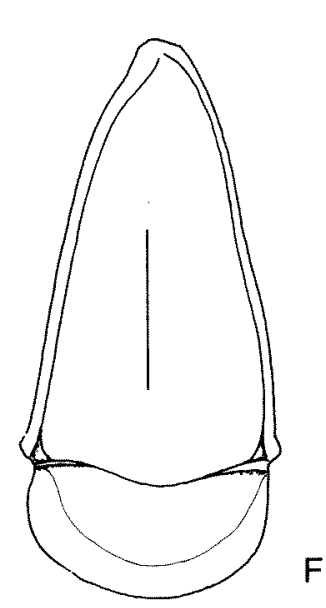

A

Figure 4 Sphallomorpha flavopicea Baehr, details of male genitalia: A, male sternum VII; B, male genital ring; C, lower surface of aedeagus; D, right paramere; E, left paramere. F, lateral view of aedeagus; Scale lines: $0.5 \mathrm{~mm}$.

the shape and elytral pattern it is fairly similar to the common and widespread S. suturalis Germar, therefore it is likely confused with the latter species, but it is easily distinguished by the acute wings of the mentum and usually also by the triangular sutural spot which is widest at base. Because the new specimens are males, the male genitalia are described for the first time.

The single specimen from Halls Creek in northern Western Australia is tentatively included in this species, because its aedeagus is identical with those of the southern specimens, and it also has the characteristic acute apex of the wings of the mentum. However, it is decidedly smaller and has only a narrow and quite indistinct elytral stripe. Hence, it may represent a related taxon, but, as the specimen is somewhat teneral, it even might be an exceptionally small specimen of $S$. flavopicea. In view of the insufficient knowledge of the ranges of most Western Australian pseudomorphines, even the very large distribution gap between the "normal" specimens which so far are only known from interior southern Western Australia, and this specimen which is recorded from the southern margin of the Kimberleys, may be rather due to this unsatisfactory knowledge.

The southern specimens were either fogged from the trunks of rough-barked Mallee eucalypts, or were collected from under bark of Salmon Gums (Eucalyptus salmonophloia).

\section{Sphallomorpha flavorufa sp. nov. Figures 5, 12, 17}

\section{Material examined}

Holotype

Australia: Western Australia: $\delta$, Harrismith, 1 April 1991, UV-light, A. Szito (WADA 27348).

\section{Etymology}

The name refers to the largely flavous to rufous upper surface.

\section{Diagnosis}

The body shape, chaetotaxy, and structure of the male genitalia suggests this is a member of the albopicta species-group (Baehr, 1992). It differs, however, from all species of this group by its colouration and colour pattern, which is more widely light and, at the same time, more faded than in all other species of the group.

\section{Description}

Measurements: length: $11.5 \mathrm{~mm}$; width: $5.9 \mathrm{~mm}$. Ratios: width pronotum/head: 1.65 ; width elytra/ pronotum: 1.11 ; width/length of pronotum: 2.51 ; length/width of elytra; 1.22 length elytra/pronotum: 3.41 .

Colour (Figure 12): head and pronotum uniformly reddish. Elytra largely yellow, though lateral 


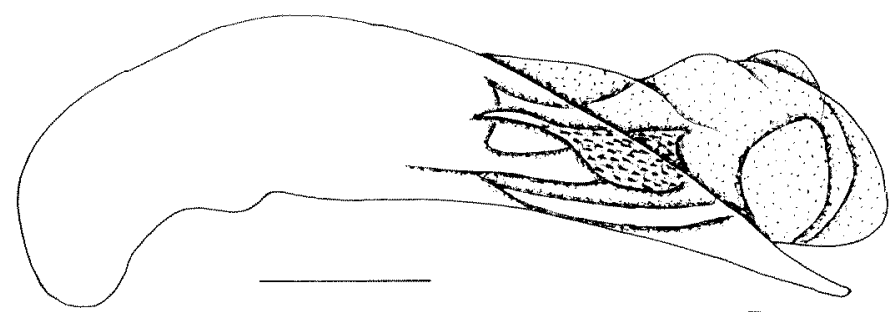

B

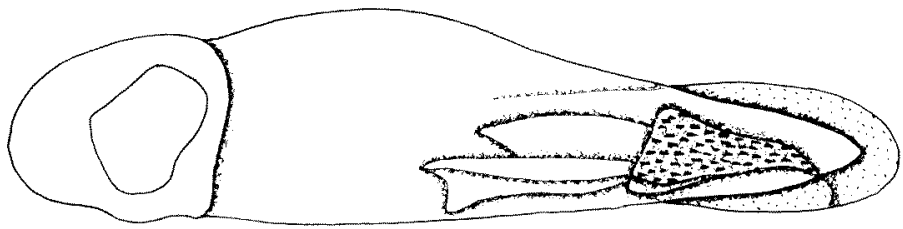

C
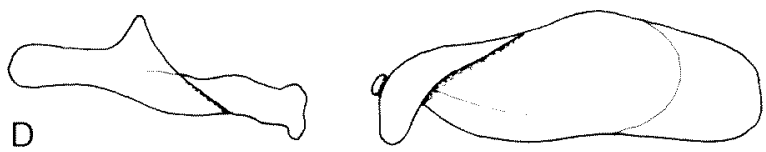

E

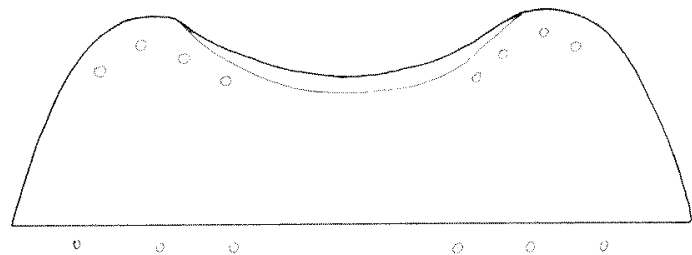

A

Figure 5 Sphallomorpha flavoruta sp. nov., details of male genitalia: A, male sternum VIl; B, male genital ring; C, lower surface of aedeagus; D, right paramere; E, left paramere. F, lateral view of aedeagus; Scale lines: $\mathrm{A}(1 \mathrm{~mm}) ; \mathrm{B}-\mathrm{F}(0.5 \mathrm{~mm})$.

margins reddish, but base except for scutellum and scutellar area dark picous. This colour narrows along suture and altogether is fading into picous which covers the narrow apex and the posterior lateral parts inside of the reddish margin. Hence, colour pattern distinct in basal half, becoming quite blurred posteriorly. Labrum, mouth parts, and antenna dark reddish to light piceous. Ventral surface of head dark reddish, rest of ventral surface reddish, centre of abdomen feebly darker. Legs piceous, femora light reddish.

Chaetotaxy (Figures 1A): supraorb: 1; preorb: 1, clyp: 1; labr: 4; ment.med: 2; ment.lat: 6-7; gloss: 4; gul: 2; postorb: 3; suborb: 11-12; pron ant: 1 short; pron.post: 1; proeps: $2-3+2-3$; marg: 18 ; st VI: 3 ; st VII: 4 ; 9 st VII: ?.

Head (Figure 12): rather wide, fairly depressed, frontal impressions barely visible. Clypeus concave, clypeal sutures distinct, elongate. Lateral border of head convex, slightly incurved in front of eves. Labrum rather wide, laterally oblique, anteriorly very gently excised. Mentum with shallow, medially slightly excised prominence. Wings of mentum rather elongate, fairly acute, subapically almost straight, oblique, medially at apex very oblique, then feebly oblique. Glossa feebly excised, border sharp. Dorsal part rather surpassing ventral, medially fairly excised, with several hairs. Terminal palpomere of labial palpus elongate, narrow, distinctly widened towards apex, though not securiform, of maxillary palpus elongate, slightly attenuate. Antenna elongate and delicate, median antennomeres c. 4- $x$ as long as wide. Microreticulation extremely dense and fine, punctuation dense and moderately fine, surface with some transverse strioles laterally of clypeal sutures and near eves, anteriorly with very fine and short, erect pilosity, in posterior half apparently without pilosity, surface rather dull. Palpi sparsely pilose. Galea with several short hairs along anterior border and at apex. Ventral surface with scattered, comparatively elongate pilosity.

Pronotum (Figure 12): fairly narrow, moderately convex. Apex with deep excision. Anterior angles markedly projecting, though the very apex obtuse Sides evenly rounded, widest in posterior third, shortly in front of posterior marginal seta, basal angles widely rounded. Base gently bisinuate Lateral margin with extremely fine border line Discal impressions rather punctiform. Microreticulation fine and dense, punctuation very dense and fine, difficult to detect, surface with many fine, irregular strioles, with extremely short, erect pilosity, rather dull.

Elytra (Figure 12): elongate, rather parallel, moderately convex. Apex wide, obliquely convex. Striae barely perceptible, only inner striae in posterior half marked by delicate rows of 
longitudinal strioles, intervals absolutely depressed. Series of marginal pores almost uninterrupted. Microreticulation of surface very fine, slightly more superficial than on fore body, therefore surface of elytra markedly glossier than that of head and pronotum. Surface with scattered, almost invisible punctures and with extremely short and fine, erect pilosity that is detectible only under high magnification.

Lower surface: prosternal process rather elongate, moderately wide, apex fairly convex, apparently impilose, ventral surface convex, evenly curved to apex. Metepisternum c. $2 \mathrm{x}$ as long as wide.

Legs: rather elongate. Metatarsus about as long as metatibia. $1^{\text {st }}$ tarsomere of metatarsus slightly shorter than $2^{\text {nd }}$ and $3^{\text {rd }}$ tarsomeres together.

Male genitalia (Figures 5A-F): sternum VII wide, with wide, very shallow, evenly rounded excision. Genital ring moderately wide, triangular, basal border convex, lateral angles rounded, basal plate rather elongate, anteriorly with shallow excision. Aedeagus elongate, narrow in apical half, apex elongate, acute, tip barely upturned. Orifice elongate. Internal sac elongate, narrow, conspicuously microtrichiate, for pattern see Figures 1B, C. Right paramere moderately elongate, apex rather elongate, gently widened. Left paramere elongate, slightly sinuate on upper and lower borders, apex transverse, little convex.

Female genitalia: unknown.

Variation: unknown.

\section{Distribution}

South-western Western Australia. Known only from the type locality (Figure 17).

\section{Habits}

The habits of this species are largely unknown. The holotype was collected at light, but like its congeners, it is certainly a bark-inhabiting species.

\section{Remarks}

The body shape, chaetotaxy, and the structure of the male genitalia of this species suggests it is a member of the albopicta species-group (Baehr, 1992), but its relationships within this group are uncertain.

\section{Sphallomorpha clypeosetosa sp. nov.} Figures 6, 13, 18

\section{Material examined}

\section{Holotype}

Australia: Western Australia: ${ }^{\star}$, Nita Downs Station, $19^{\circ} 05^{\prime} \mathrm{S}, 121^{\circ} 41^{\prime} \mathrm{E}$, Western Australia, January 1981, A.M. and M.J. Douglas (WAM 45174).

\section{Paratypes}

Australia: Western Australia: 14 ठ , 6 \&, same data (WAM 45154-73; CBM 45164/65).

\section{Etymology}

The name refers to the unique profuse setosity of the clypeus.

\section{Diagnosis}

This species is distinguished from all known species of Sphallomorpha by the multisetose clypeus and the uniformly light reddish colour.

\section{Description}

Measurements: length: $8.3-9.5 \mathrm{~mm}$; width: 4.15 $4.75 \mathrm{~mm}$. Ratios: width pronotum/head: $1.66-1.73$; width elytra/pronotum: 1.11-1.16; width/length of pronotum: 2.22-2.31; length/width of elytra; 1.28 1.31; length elytra/pronotum: 3.20-3.42.

Colour (Figure 13): upper and lower surfaces, including mouth parts, antennae, and legs, uniformly reddish.

Chaetotaxy (Figures 6A, B, D, E): supraorb: 1; preorb: 1, clyp: 3-7; labr: 4-6; ment.med: 2; ment.lat: 5; gloss: 6; gul: 2; postorb: 2-3; suborb: 1-2; pron.ant: -; pron.post: -; proeps: -; marg: 11-12; st VI: 3-5; \& st VII: 3-4; 우 st VII: 4-5.

Head (Figures 6A-C): short and wide, fairly depressed, with conspicuous, comparatively deep, circular frontal impressions. Eyes large, convex. Clypeus deeply concave, clypeal setae arising from remarkably large pits, clypeal sutures distinct, elongate, impressed, and with irregular grooves. Lateral margin of head anteriorly very oblique, even slightly concave, posteriorly suddenly convex, with a distinct though obtuse angle in middle, slightly incurved in front of eyes. Labrum wide, short, laterally convex, anteriorly gently convex and slightly asymmetrical, because the right part is slightly more produced, in middle slightly raised, with 4-6 elongate setae which arise from deep and large pits. Mentum gently convex in middle, with a narrow swelling along anterior margin. Wings of mentum short, wide, though apex angulate, subapically convex, medially oblique. Lateral mental setae remarkably elongate and arising from deep and wide pits. Glossa deeply excised, border angulate, setae short. Dorsal part well surpassing ventral, medially barely excised, without bristles or hairs. Terminal palpomere of labial palpus elongate, narrow, even slightly narrowed to the slightly oblique apex, terminal palpomere of maxillary palpus narrow and elongate. Antenna short, median antennomeres of antenna c. $1.75 \mathrm{x}$ as long as wide. Microreticulation dense and fine, superficial, punctuation very fine, barely visible even under high magnification, surface almost not striolate, without extremely short and scattered, erect pilosity that is barely visible even under high magnification, 

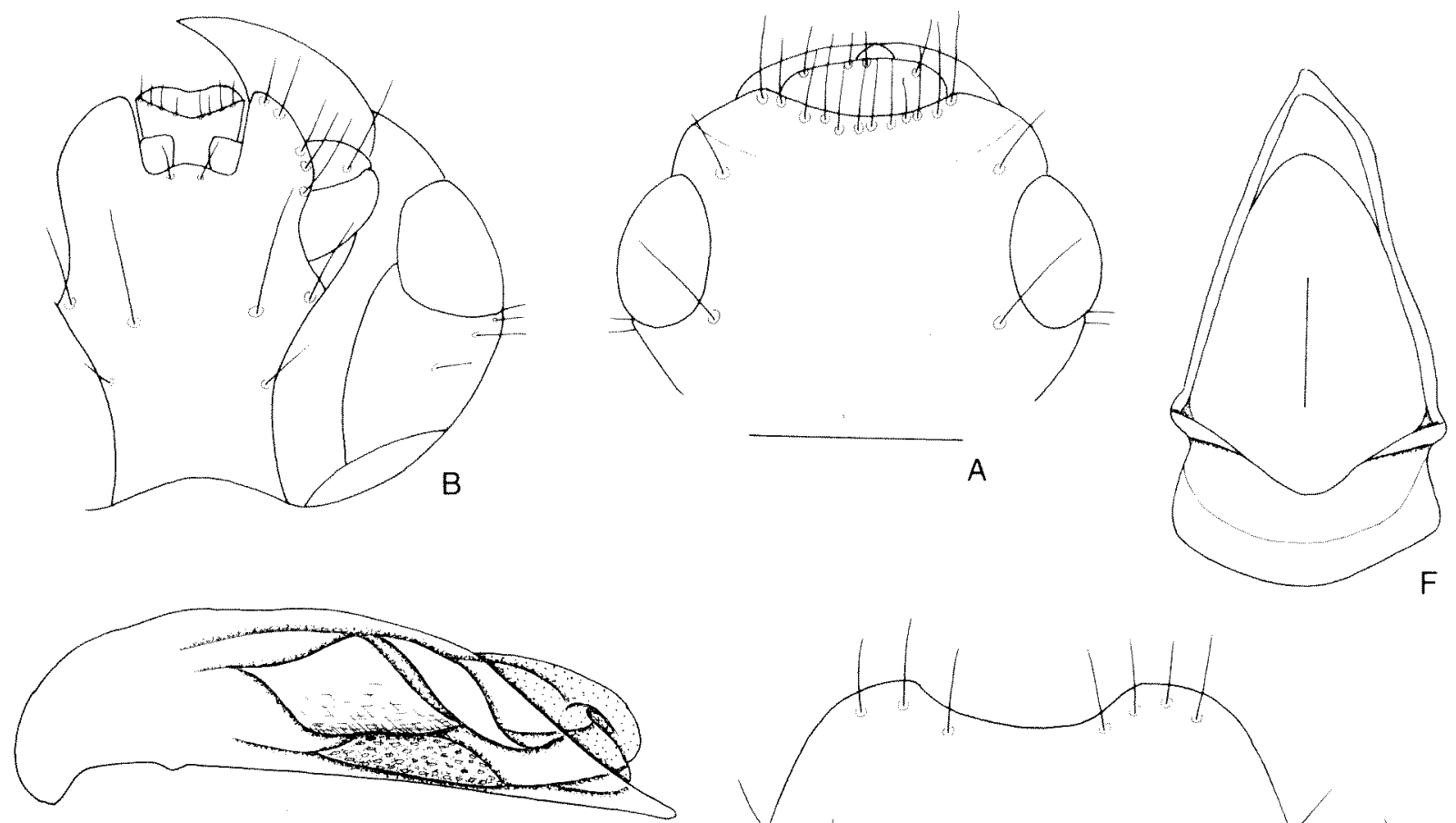

G

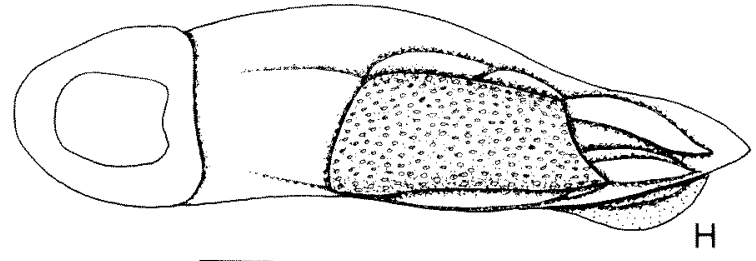

A

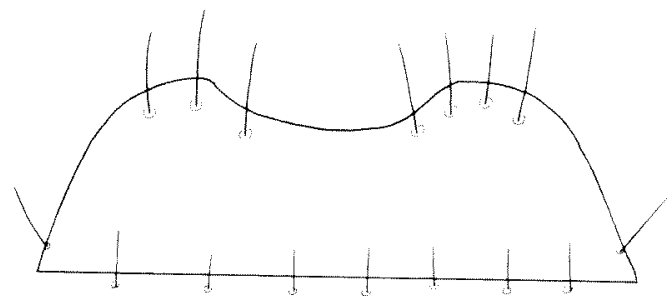

$\mathrm{D}$
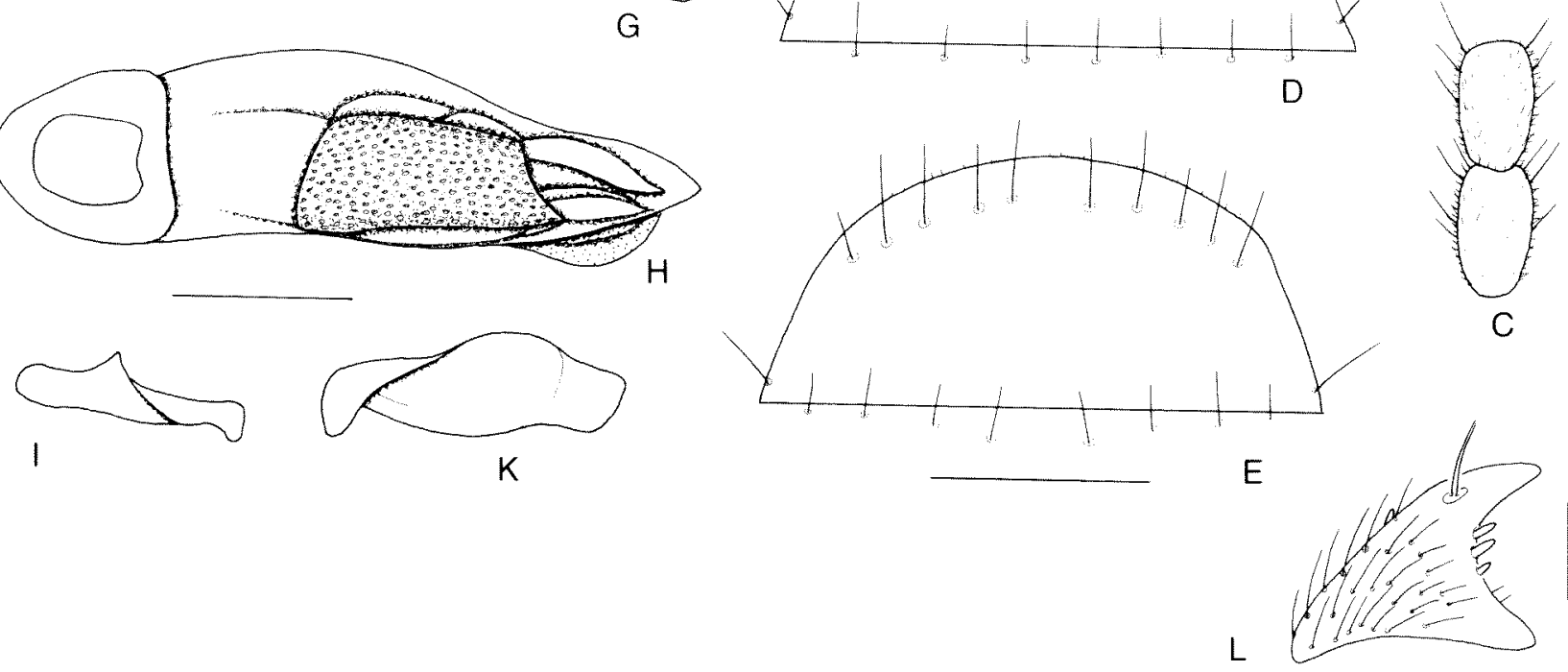

Figure 6 Sphallomorpha clypeosetosa, sp. nov, details of head and genitalia: A, dorsal surface of head; B, lower surface of head; C, median antennomeres; D, male sternum VII; E, female sternum VII; F, male genital ring; $\mathrm{G}$, lateral view of aedeagus; $\mathrm{H}$, lower surface of aedeagus; l, right paramere; $\mathrm{K}$, left paramere; $\mathrm{L}$, female stylomere 2. Scale lines: A, D, E $(1 \mathrm{~mm}) ; \mathrm{F}-\mathrm{K}(0.5 \mathrm{~mm}) ; \mathrm{L}(0.1 \mathrm{~mm})$.

surface glossy. Palpi with rather elongate, but scattered pilosity. Galea with some short hairs at apex. Lower with the same, almost invisible pilosity as the upper surface.

Pronotum (Figure 13): short and wide, moderately depressed, laterally little explanate. Apex with rather shallow excision which is slightly convex in middle. Anterior angles moderately protruding, wide, apex faintly obtuse. Sides evenly convex, widest slightly in front base which is widely rounded. Base gently bisinuate and projecting in middle. Lateral margin with fine border line. Dorsal surface rather uneven, discal impressions fairly well developed and about linear, also with several irregular impressions.
Microreticulation very fine, dense, somewhat superficial, punctuation barely visible, surface with some fine, irregular strioles, with extremely fine and short, scattered pilosity, rather glossy.

Elytra (Figure 13): fairly elongate, not much wider than pronotum, laterally almost parallel, moderately convex. Apex moderately wide, slightly oblique, almost straight. Striae virtually not impressed, only marked by moderately fine, spaced punctures, even inner intervals absolutely depressed. Series of marginal punctures widely uninterrupted in middle, at shoulders not irregular, arranged in a fairly straight line. Microreticulation very fine, superficial, almost isodiametric though arranged an about transverse rows, sparse 
punctuation present but barely recognizable, surface virtually impilose, glossy.

Lower surface: prosternal process rather elongate, moderately wide, apex gently rounded, ventral surface convex, feebly curved to apex, with a single elongate seta at apex. Metepisternum almost $2 x$ as long as wide.

Legs: comparatively short. Metatarsus slightly shorter than metatibia. Upper surface of tarsi extremely sparsely pilose. $1^{\text {st }}$ tarsomere of metatarsus about as long as $2^{\text {nd }}$ and $3^{\text {rd }}$ tarsomeres together.

Male genitalia (Figures 6D, G-K): sternum VII moderately wide, with wide, shallow excision and with 3-4 setae on either side. Genital ring wide, triangular, basal border asymmetrically convex, lateral angles little rounded, basal plate fairly elongate, anteriorly deeply excised, arms more or less distinctly sinuate. Aedeagus rather short, compact, wide, somewhat asymmetrical, lower surface straight, apex rather wide but angulate. Orifice rather short. Internal sac with a large, conspicuously knobbed plate at bpttom, for pattern see Figures 1e, f. Right paramere moderately elongate, with rather wide apex, basal part straight. Left paramere elongate, remarkably curved, with oblique, almost transversal apex.

Female genitalia (Figures 6E, L): sternum VII elongate, apical border convex, with 5 rather elongate setae on either side, and with a fringe of short hairs at matgin. Stylomere 2 short, with short, obtuse apex, with 3 small ves of decreasing size, one small des and 2 ns. Pilosity dense and very elongate.

Variation: rather little variation noted in size and body shape, but the number of labral and clyeal setae varies to a considerable degree.

\section{Distribution}

This species is found in north-Western Australia near the edge of the Great Sandy Desert. It is known only from the type locality (Figure 18).

\section{Habits}

The habits of this species are largely unknown. The series was sampled "mostly from swimming pool of vicinity of homestead light". These are quite uncommon sampling circumstances, because pseudomorphines generally are bark-inhabiting animals which, moreover, are quite rarely found at light.

\section{Relationships}

In view of the particular clypeal, labral, and labial setation, this species does not fit any of the speciesgroups proposed by Baehr (1992) and hence is the single representative of its own group.

The exceptional number and insertion of the clypeal setae, the variable number of labral setae, the extreme length of the lateral mental setae, and the colour, shape and structure of the aedeagus makes this an unique, quite outstanding species.

\section{Genus Adelotopus Hope, 1834}

Adelotopus Hope, 1834: 11; Baehr, 1997: 51.

\section{Type species}

Adelotopus gyrinoides Hope, 1834, by monotypy.

\section{Remarks}

With slightly more than 130 described species Adelotopus is the second largest genus of Pseudomorphinae. With respect to the reduced chaetotaxy and the unique foliaceous female stylomeres this genus is rather apotypic within Pseudomorphinae and shares the ovovivipary with all other genera except Sphallomorpha and Cryptocephalomorpha (see note above). The bulk of the species of Adelotopus are Australian, with a few species recorded from New Guinea, the Moluccas, the Solomon Islands, Java and southernmost mainland Malaysia. In Australia species of Adelotopus occur in most regions, provided some tree growth is present, but apparently not in rainforest. Species of this genus are found as well under bark of bark shedding eucalypts as in the cracks of the thick bark of various sorts of trees.

\section{Adelotopus brevipennis Macleay, 1888}

Adelotopus brevipennis Macleay, 1888: 459; Baehr, 1997: 96

\section{New material examined}

Australia: Western Australia: $1 \delta$, CALM Pilbara Survey, site WYW01, $2 \mathrm{~km}$ E. of Mt. Minnie, $22^{\circ} 06^{\prime} 14.9^{\prime \prime} \mathrm{S}, 115^{\circ} 34^{\prime} 04.2^{\prime \prime} \mathrm{E}, 27$ November 2003-30 April 2004 (WAM 67925).

\section{Remarks}

Adelotopus brevipennis is a rather common species throughout tropical northern Australia, but in Western Australia it also occurs south of the Great Sandy Desert, and has been already recorded from lower Fortescue and Millstream areas (Baehr 1997). The new specimen was collected using a glycol pitfall trap.

Adelotopus pilbarae sp. nov. Figures 7, 14, 17

\section{Material examined}

\section{Holotype}

Australia: Western Australia: ठ, CALM Pilbara 
Survey, site WYE03, $18 \mathrm{~km} \mathrm{W.} \mathrm{of} \mathrm{Mt.} \mathrm{De} \mathrm{Courcay,}$ $22^{\circ} 44^{\prime 24.7}$ 'S, $116^{\circ} 27^{\prime} 40.1^{\prime \prime E}, 26$ November 2003-2 May 2004 (WAM 67926).

\section{Paratypes}

Australia: Western Australia: 1 ठ, 1 \& same data (WAM 67927/8); 1 d, 3 \&, CALM Pilbara Survey, site RHNW02, $24 \mathrm{~km} \mathrm{WSW}$. of Mt. Marsh, 22 32'9"S, 118 59'51.3"E, 20 November 2003-22 May 2004 (DEC, CBM, WAM 67929).

\section{Etymology}

The name refers to the occurrence of this species in the Pilbara Region of Western Australia.

\section{Diagnosis}

Adelotopus pilbarae is a species of the brevipennis species-group (Baehr 1997), characterized by the uniformly reddish colour, rather small size, and wide aedeagus bearing a rather acute apex. It is distinguished from the most similar species, $A$. rufescens Baehr, by its smaller size; from $A$. flavus Baehr by the angulate basal angle of the pronotum and the darker colour; from $A$. elongatulus Macleay by the wider body; and from $A$. piceus Baehr by its lighter colour and the angulate apex of the aedeagus.

\section{Description}

Measurements: length: 5.2-5.9; width: $2.5-2.7 \mathrm{~mm}$. Ratios. Width/length of pronotum: $1.77-1.83$; width base/apex of pronotum: $1.57-1.60$; width pronotum/ head: 1.69-1.74; length/width of elytra: 1.40-1.48; length elytra/pronotum: $2.60-2.68$.
Colour (Figure 14): upper and lower surface including mouth parts, antennae, and legs uniformly reddish, head commonly slightly darker, lateral margins of pronotum and elytra barely lighter.

Head (Figure 14): short and wide, rather depressed. Anterior border convex, lateral angle rounded, angle laterally slightly projecting, lateral borders oblique. Clypeal suture semicircular, in middle interrupted. Labrum narrow, apex concave. Antennal groove laterally sharply bordered, lateroposteriorly with carinate area. Mental tooth triangular, short, apex acute. Wings of mentum wide, laterally rounded, apex rectangular. Glossa wide, tongue-like, apically widely rounded, ventrally with distinct keel, at border with c. 12 elongate setae and additional pilosity on upper and lower surface and along border. Terminal palpomere of maxillary palpus widened, though barely securiform. Terminal palpomere of labial palpus wide, securiform. Antenna moderately short, $8^{\text {th }}-9^{\text {th }}$ antennomeres slightly $<1.5 x$ as wide as long. Microreticulation fine, distinct, punctuation fine, dense, well visible under high magnification, surface with a shallow sulcus medially of eyes, apparently impilose, fairly dull. Ventro-laterally of eyes with a row of short setae. Suborbital field at least laterally punctate and setose. Both palpi rather sparsely setose, gula almost asetose.

Pronotum (Figure 14): wide, depressed, base wide, apex rather narrow. Apical angles produced, acute, attaining the middle of the eyes. Apex deeply, rectangularly excised, faintly convex in excision, bordered. Sides convex throughout, near base even feebly curved inwards, widest slightly in
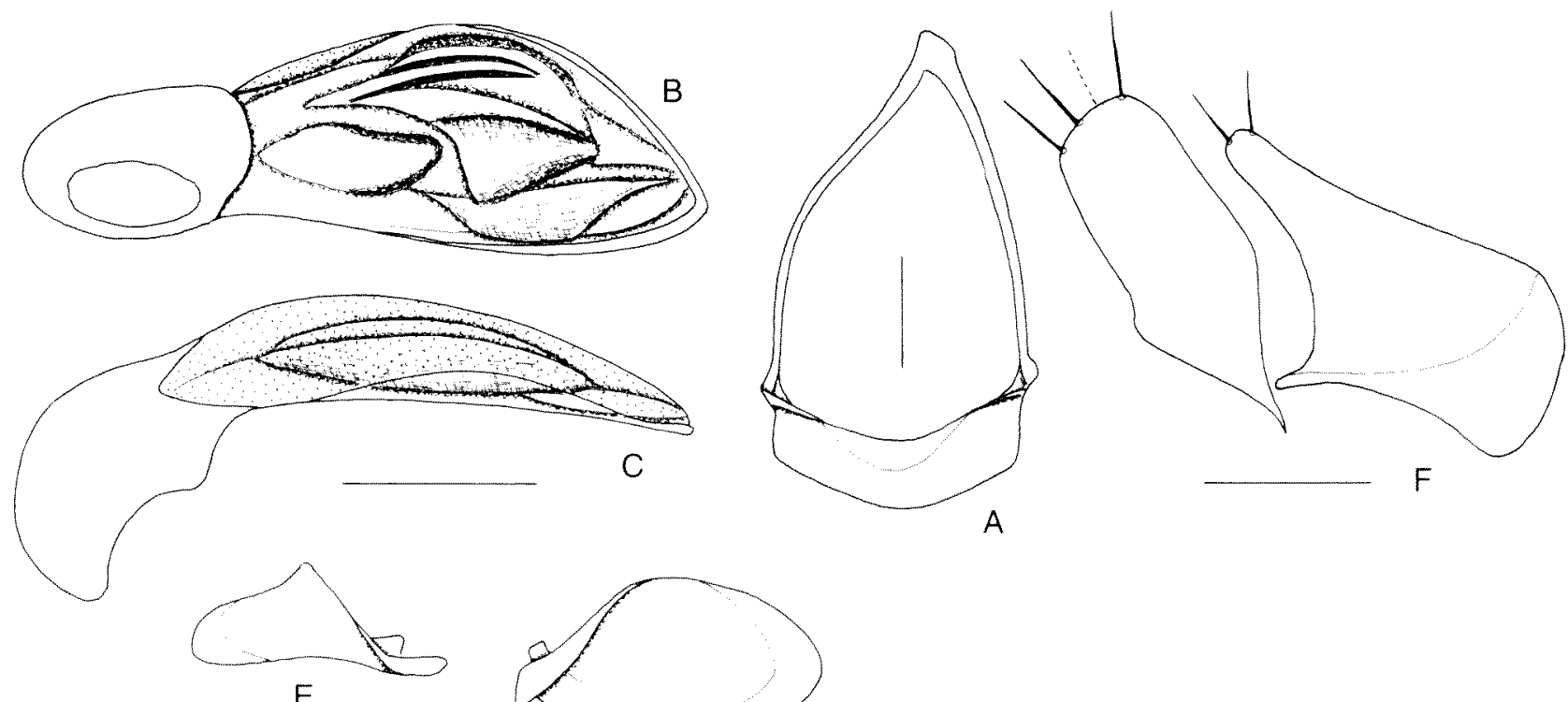

C

A

Figure 7 Adelotopus pilbarae, sp. nov, details of male and female genitalia: A, male genital ring; B, lower surface of aedeagus; $C$, lateral view of aedeagus; D, left paramere; $E$, right paramere; $F$, female stylomere and lateral plate. Scale lines: $A-E(0.25 \mathrm{~mm}) ; \mathrm{F}(0.1 \mathrm{~mm})$. 
front of base. Sides faintly bordered, explanate, but not channelled. Basal angles almost rectangular, distinctly produced backwards, apex obtuse. Base laterally concave, in not or but feebly middle produced, narrowly bordered. Surface near base with more an extremely shallow transverse impression. Microreticulation fine, though distinct, isodiametric to somewhat irregular, punctuation dense and moderately fine, surface with distinct network of fine, irregular strioles, somewhat coriaceous, very sparsely pilose with extremely short, erect hairs, dull.

Elytra (Figure 14): moderately elongate, depressed, in basal two thirds parallel, then gently narrowed near apex. Apex wide, faintly oblique, truncature feebly convex, apical angles shortly rounded. Humeri distinct, basal margin slightly oblique, without setae behind humerus. Marginal channel rather narrow, completely visible from above. Basal border incomplete, reaching only slightly inside of middle of base, ending abruptly. Lateral border asetose. Series of umbilical pores consisting of 6 pores behind humerus. Setae very short. Striae including sutural stria absent. Microreticulation fine, though distinct, isodiametric to irregularly transverse, somewhat superficial, less distinct than on pronotum, not coriaceous, punctuation fine, moderately dense, much finer and sparser than on pronotum, apical punctures somewhat rasp-like. Surface rather sparsely pilose with extremely short, erect hairs, rather dull.

Lower surface: prosternal process rather elongate, narrow, straight, depressed, apex narrow, straight, faintly rounded off, shortly setose. Metepisternum moderately elongate, c. $1.8 \mathrm{x}$ as long as wide, posteriorly not constricted nor hollowed. Abdominal sterna including sternum VI apparently without setae at apical border. Lower surface densely punctate and pilose.

Legs: elongate, $1^{\text {st }}$ tarsomere of protarsus slightly longer than wide, tibial groove of profemur moderately deep, anterior plate only at apex distinctly overlapping the groove, posterior border of groove sharp. Femur comparatively narrow. Metatibia narrow and elongate, c. $6 \times$ as long as wide, $1^{\text {st }}$ tarsomere of metatarsus $>2.5 \times$ as long as wide. Male protarsus not widened.

Male genitalia (Figures 7A-E): genital ring rather wide, triangular, but markedly asymmetrical, with wide, short base. Sternum VII moderately wide, apically moderately deeply excised, basally feebly convex, lateral parts small. Aedeagus mediumsized, depressed, in middle much widened, asymmetrical. Lower almost straight. Apex angulate. Orifice very elongate, internal sac fairly complex, with a fold near apex. Both parameres rather large and elongate, both with rounded apex, left considerably larger than right.

Female genitalia (Figure $7 \mathrm{~F}$ ): stylomere remarkably parallel-sided, virtually not widened in middle, apex wide, gently rounded off, with 3-4 subapical setae. Lateral plate elongate, with 2 apical setae.

Variation: apart from some differences in relative width of pronotum and elytra, and in distinctness of microreticulation and punctuation of upper surface little variation noted.

Vivipary: not confirmed in the examined material.

\section{Distribution}

This species occurs in the Pilbara region, situated in north-Western Australia (Figure 17).

\section{Habits}

The habits of $A$. pilbarae are largely unknown. All specimens were collected in glycol pitfall traps. Most likely this is a bark-inhabiting species that may dwell under loose eucalypt bark like almost all of its congeners.

\section{Relationships}

This species is a member of the brevipennis species-group (Baehr 1997), and is probably most similar to $A$. rufescens Baehr and A. flavus Baehr from extreme north-Western Australia and the northernmost Northern Territory.

\section{Adelotopus coriaceus Baehr, 1997 Figure 18}

Adelotopus coriaceus Baehr, 1997: 125.

\section{New material examined}

Australia: Western Australia: 1 \&, CALM Pilbara Survey, site PW10, $3.4 \mathrm{~km} \mathrm{~N}$. of Millstream, $21^{\circ} 38^{\prime} 48.2^{\prime \prime S}, 117^{\circ} 3^{\prime} 32.8^{\prime \prime} \mathrm{E}, 8$ May-11 October 2004 (WAM 67931).

\section{Remarks}

This peculiar species was previously known from two specimens from Yuendumu in western-central Northern Territory. The new record is the first from Western Australia. The specimen was collected in a glycol pitfall trap, but certainly this species is a bark-inhabiting animal like its congeners.

\section{Adelotopus puncticollis angustemaculatus Baehr, 1997 \\ Figure 17}

Adelotopus puncticollis angustemaculatus Baehr, 1997: 209.

\section{New material examined}

Australia: Western Australia: 1 \&, 2 , site WA06/184, Booyagin Rock, $25 \mathrm{~km} \mathrm{SW}$. of Brookton, 32.47217º, 116.88507 E, 295 m, 7 March 2006, M. Baehr (CBM) 


\section{Remarks}

Adelotopus puncticollis angustemaculatus is the western subspecies of A. puncticollis, and was recorded from few localities and specimens from the southern part of Western Australia (Baehr 1997) The new record extends the recorded range perceptibly to the west. The specimens were fogged from the bark of Red Tingle (Eucalyptus jacksonii).

\section{Adelotopus basalis sp. nov.}

Figures 8, 15, 18

\section{Material examined}

\section{Holotype}

Australia: Western Australia: o, site WA06/162, $35 \mathrm{~km} \mathrm{~W}$. of Leinster, 27.96406 ${ }^{\circ} \mathrm{S}, 120.43070 \mathrm{E}, 507$ m, 2 March 2006, M. Baehr (WAM 67930).

\section{Paratype}

Australia: Western Australia: $1 \%$, same data as holotype (CBM).

\section{Etymology}

The name refers to the largely reddish elytra which are dark only near the base.

\section{Diagnosis}

Adelotopus basalis is a member of the seriepunctatus species-group (Baehr 1997), characterized by the almost completely reddish elytra which leave a narrow basal border only dark, and the acute apex of the aedeagus. It is distinguished from the most similar species $A$. puncticollis, by more extended red colouration on the elytra, the slightly smaller size, and a more acute apex of the aedeagus.

\section{Description}

Measurements: length: 4.4-4.6 mm; width: 1.5-1.7 $\mathrm{mm}$. Ratios. Width/length of pronotum: 1.31 ; width base/apex of pronotum: $1.36-1.39$; width pronotum/ head: 1.45-1.4; length/width of elytra: 1.67-1.70; length elytra/pronotum: $2.26-2.30$.

Colour (Figure 15): head, pronotum, and base of elytra and the narrow margins of the elytra in basal two thirds black. Black basal spot on elytra triangular, most of elytra red. Lower surface of head and thorax black, abdomen reddish, darjer in middle. Mouth parts, antennae, and legs reddish, tibiae and tarsi barely darker.

Head (Figure 15): rather short, moderately wide, rather depressed. Anterior border gently convex, lateral angle rounded, laterally projecting, lateral borders concave behind eyes. Clypeal suture barely visible. Labrum rather wide and short, moderately overlapped by the clypeus, apex feebly concave. Antennal groove laterally sharply bordered, lateroposteriorly with slightly angulate area. Mental tooth triangular, short, apex acute. Wings of mentum wide, laterally oblique, apex acutely angulate. Glossa wide, tongue-like, apically convex, ventrally with indistinct keel, at border with c. 12 elongate setae and additional pilosity on upper and lower surface and along border. Terminal palpomere of maxillary palpus elongate, almost parallel, not securiform. Terminal palpomere of labial palpus
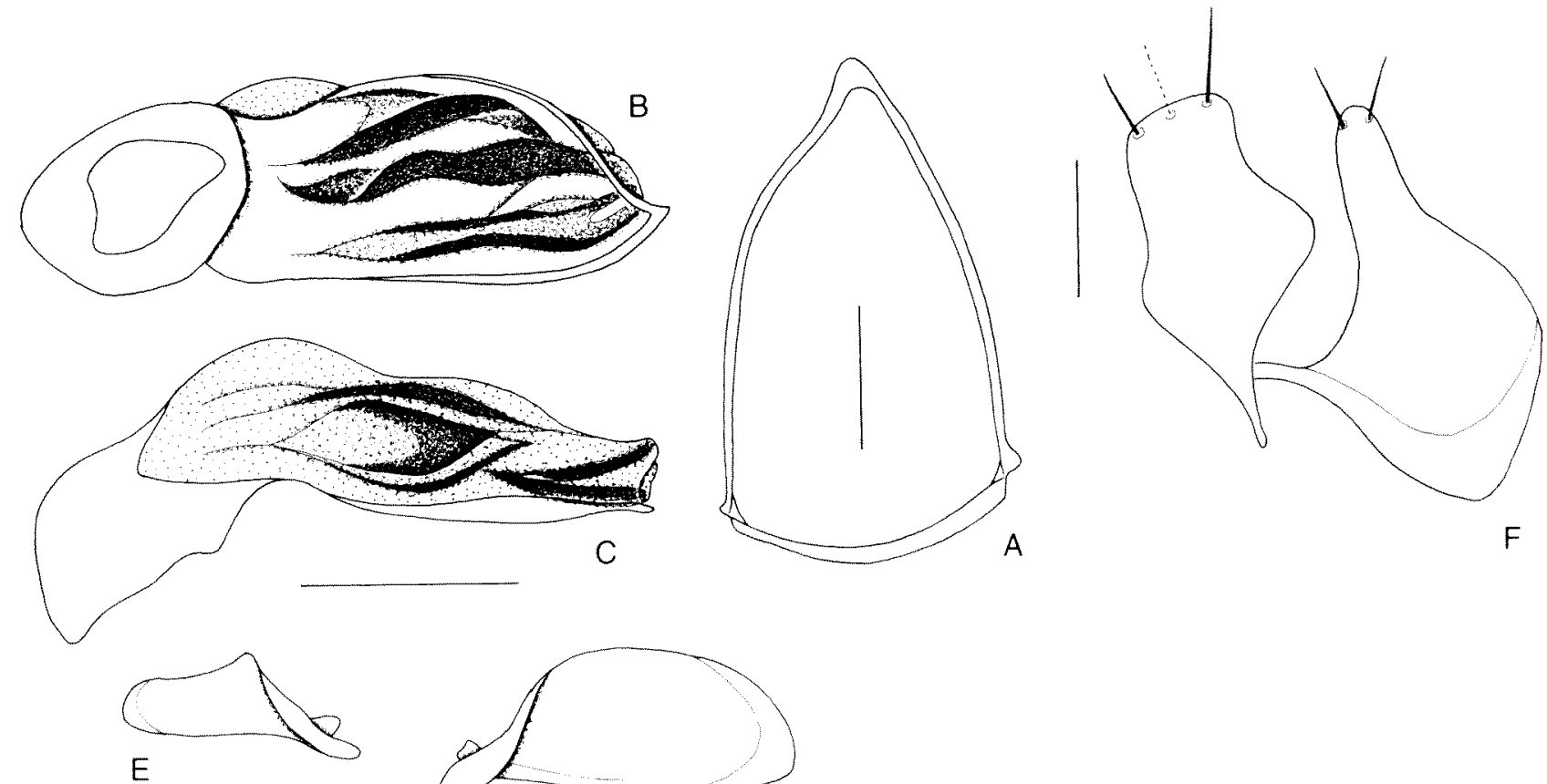

Figure 8 Adelotopus basalis sp. nov, details of male and female genitalia: A, male genital ring; B, lower surface of aedeagus; $C$, lateral view of aedeagus; D, left paramere; $E$, right paramere; F, female stylomere and lateral plate. Scale lines: A-E $(0.25 \mathrm{~mm}) ; \mathrm{F}(0.1 \mathrm{~mm})$. 
wide, distinctly securiform. Antenna short and wide, fairly parallel, $8^{\text {th }}-9^{\text {th }}$ antennomeres c. $1.8 \times$ as wide as long. Microreticulation absent, punctuation dense, somewhat irregular, punctures rather coarse but of slightly different size. Surface with weak sulcus medially of eyes, impilose, glossy. Ventrolaterally of eyes with a row of short setae. Suborbital field impunctate. Gula impilose.

Pronotum (Figure 15): rather narrow and fairly elongate, convex, slightly wider than long, more or less conical, base distinctly wider than apex, widest near base. Apical angles little produced, at apex obtuse, fairly oblique, attaining posterior border of eyes. Apex gently excised, slightly convex in excision, with extremely superficial, barely recognizable border line. Sides little convex, slightly oblique. Margins very narrow, narrowly chanelled, coarsely bordered. Basal angles about rectangular but obtuse at apex. Base faintly concave, very superficially bordered. Surface near base without recognizable transverse impression. Microreticulation absent, punctuation dense, coarse, though becoming finer and less dense towards base, anteriroly with very fine punctures between the coarse ones, surface impilose, highly glossy.

Elytra (Figure 15): narrow and elongate, convex, lateral margins almost parallel. Apex wide, transverse, truncature markedly convex, in middle distinctly drawn in, apical angles widely rounded off. Humeri rounded, basal margin slightly oblique, without setae behind shoulders. Marginal channel narrow throughout, partly concealed. Basal border incomplete, attaining outer third of base. Lateral border asetose. Series of umbilical pores consisting of 6 or 7 rather spaced pores behind shoulder, but pores small and difficult to detect. Setae fairly elongate. Scutellum very wide. Striae including sutural stria inconspicuous, marked by rows of moderately fine punctures. Microreticulation absent, each interval with fine, sparse, irregular, not rasp-like punctures, surface asetose, markedly glossy.

Lower surface: prosternal process rather elongate, moderately wide, convex, apex wide, convex, passing over in an almost right angle from ventral surface, barely setose. Metepisternum very elongate, c. $2.2 \mathrm{x}$ as long as wide, in posterior third not hollowed, but becoming very narrow towards apex. Abdominal sterna with 1 elongate seta each side. Lower surface very sparsely punctate and barely pilose.

Legs: rather elongate, $1^{\text {st }}$ tarsomere of protarsus slightly wider than long, tibial groove of profemur moderately deep, anterior plate overlapping the groove only for apical forth, posterior border of groove sharp. Femur wide. Metatibia elongate, c, $5.5 \mathrm{x}$ as long as wide, $1^{\text {st }}$ tarsomere of metatarsus $\mathrm{c}$. $2.4 \times$ as long as wide.

Male genitalia (Figures $8 \mathrm{~A}-\mathrm{E}$ ): genital ring rather wide, convex, slightly asymmetrical, with slightly asymmetrical, very short base. Sternum VII rather wide, apically obliquely convex, with rather deep excision, base faintly excised, basal angles rounded, lateral parts fairly short. Aedeagus short and wide, moderately depressed, in middle markedly widened, strongly narrowed to apex, markedly asymmetrical. Basal part fairly short, moderately bent. Lower surface very convex. Apex very acute, dentiform, curved to left side. Orifice very elongate, internal sac complex, apparently without a distinct oblique fold near apex. Both parameres elongate, rather parallel, with widely rounded apex, left paramere considerably larger than right.

Female genitalia (Figure 8F): stylomere wide, markedly widened in middle, both median and lateral borders slightly concave, apex oblique and gently convex, with 2-3 elongate apical setae. Lateral plate short, with 2 elongate apical setae.

Variation: in view of the limited material, extremely little variation noted.

Vivipary: not confirmed in the examined material.

\section{Distribution}

This species is known only from the type locality, located in central Western Australia (Figure 18).

\section{Habits}

The habits of this species are largely unknown. Both known specimens were collected by fogging the rough bark of Mulga Acacias (Acacia aneura) in open Mulga country.

\section{Relationships}

According to the body shape, surface structure, colouration, and structure of the aedeagus, this species is most similar to Adelotopus puncticollis Notman.

\section{Adelotopus rubiginosus Newman, 1856 Figure 19}

Adelotopus rubiginosus Newman, 1856: 128; Baehr, 1997: 210; Baehr, 2002: 112.

\section{New material examined}

Australia: Western Australia: 4 o, 3 q, site WA06/98, Millie Soak, $10 \mathrm{~km} \mathrm{~N}$. of Cue, $27.29033^{\circ} \mathrm{S}$, $117.91034^{\circ} \mathrm{E}, 424 \mathrm{~m}, 2-3$ February 2006, M. Baehr (CBM); 1 \&, site WA06/149, $45 \mathrm{~km} \mathrm{~N}$. of Kumarina Roadhouse, $24.34257^{\circ} \mathrm{S}, 119.69421^{\circ} \mathrm{E}, 637 \mathrm{~m}, 23$ February 2006, M. Baehr (CBM); 1 \&, 1 \%, Culham, $31^{\circ} 25^{\prime}$ S, $116^{\circ} 26^{\prime} \mathrm{E}, 18$ December 1994 , R.P. McMillan (WAM 45104-5).

\section{Remarks}

Adelotopus rubiginosus is a widespread and common eastern and southern species (Baehr 1997). 
All previously known specimens of this species from Western Australia (including the type of the junior synonym $A$. castaneus Castelnau), lack any precise locality data. Hence, the new specimens are the first recent and reliable records of $A$. rubiginosus from Western Australia.

The new specimens were fogged from roughbarked blackbutt-like eucalypts (Eucalyptus nr. patens) and from trunks of Mulga Acacias (Acacia aneura), Those from Culham were sampled "under bark".

\section{Adelotopus houstoni Baehr, 1997}

Figures 9, 19

Adelotopus houstoni Baehr, 1997: 224; Baehr, 2002 : 121.

\section{New material examined}

Australia: Western Australia: 2 \&, 3 q, site WA06/152, $70 \mathrm{~km} \mathrm{~N}$. of Meekatharra, 26.03523 S, $118.68807^{\circ} \mathrm{E}, 539 \mathrm{~m}, 24$ February 2006, M. Baehr (CBM, WAM 67933); 1 q, site WA06/153, $10 \mathrm{~km} \mathrm{S.}$ of Meekatharra, $26.68060^{\circ} \mathrm{S}, 118.45109^{\circ} \mathrm{E}, 584 \mathrm{~m}, 24$ February 2006, M. Baehr (CBM); 1 \&, CALM Pilbara Survey, site PE05, $18.5 \mathrm{~km} \mathrm{SE}$. of Mt. Florance Homestead, $21^{\circ} 53^{\prime} 29.5^{\prime \prime} \mathrm{S}, 118^{\circ} 0.8^{\prime \prime} \mathrm{E}, 24$ November 2003-7 Mav 2004 (WAM 67934); 1 9, CALM Pilbara Survey, site RHNC09, $20 \mathrm{~km}$ WNW. of Rhodes Ridge, 233'13.8"S, $119^{\circ} 10^{\circ} 36.8^{\prime \prime} \mathrm{E}, 19$ November 2003-25 May 2004 (WAM 67935); 1 \%, CALM
Pilbara Survey, site RHNE09, $25 \mathrm{~km}$ NE. of Moorimoordinina Native Well, $22^{\circ} 2455.6^{\prime \prime} \mathrm{S}$,

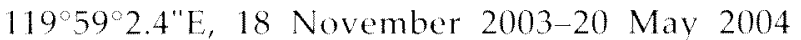
(WAM 67936); 1 \&, site WA06/20, $46 \mathrm{~km} \mathrm{NE}$. of Peak Charles, 32.64199 S, 121.50504 E, 237 m, 27 January 2006, M. Baehr (CBM).

\section{Description}

\section{Male}

Measurements: length: $4.5-5.2 \mathrm{~mm}$; width: $2.0-$ $2.25 \mathrm{~mm}$. Ratios. Width/length of pronotum: $1.66-$ 1.76; width base/apex of pronotum: 1.39-1.48; width pronotum/head: 1.53-1.60; length/width of elytra: 1.49-1.55; length elytra/pronotum: 2.52-2.62.

Male genitalia (Figures $9 \mathrm{~A}-\mathrm{E}$ ): genital ring rather wide, slightly convex, little asymmetrical, with rather elongate apex, with slightly asymmetrical, rather short, fairly excised base. Sternum VII very wide, apically evenly convex, with moderately deep excision, base faintly bisinuate, in middle markedly convex, basal angles obtusely rounded, lateral parts elongate. Aedeagus short, depressed, in middle very much widened, slightly asymmetrical, right side even concave near base. Basal part rather long, markedly bent. Lower surface straight to gently concave, markedly striped. Lateral border narrow. Apical narrowed part comparatively short, apex angulate but at tip obtuse, very slightly asymmetrical. Orifice very elongate, internal sac complex, with a large oblique fold near apex. Both
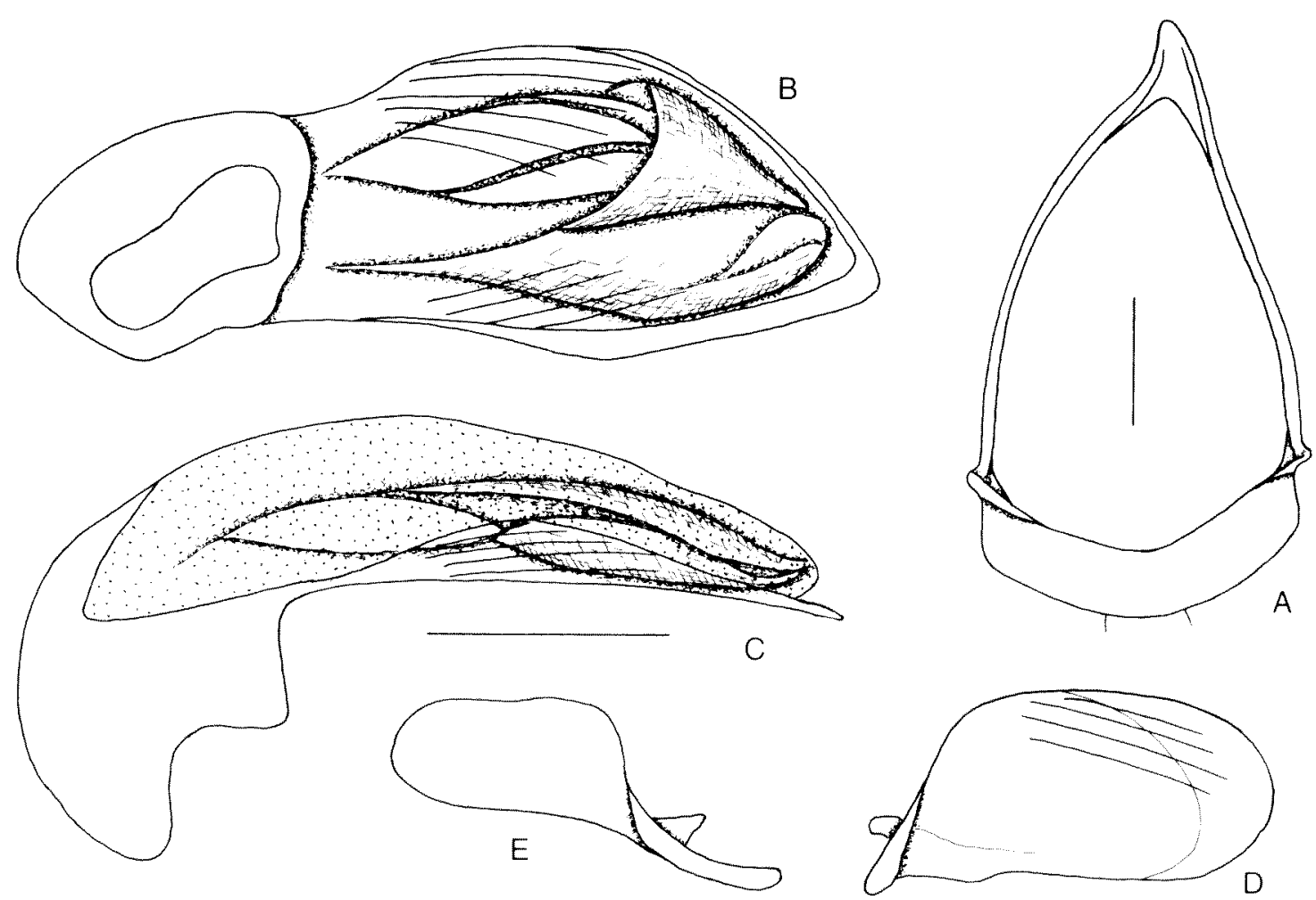

C

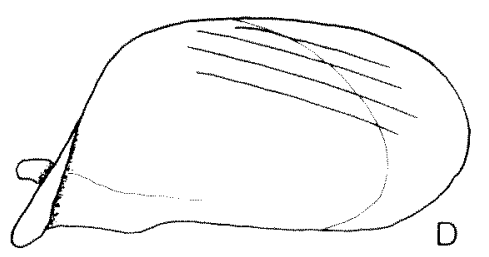

Figure 9 Adelotopus houstoni Baehr, details of male genitalia: (A), male genital ring; (B), lower surface of aedeagus; (C), lateral view of aedeagus; (D), left paramere; (E), right paramere. Scale lines: $0.25 \mathrm{~mm}$. 
parameres rather elongate and parallel, at apex widely rounded off, left paramere considerably larger.

\section{Remarks}

This species was previously known only from the female holotype captured near Banjiwarn Homestead, north-east of Wiluna. In external and genitalic morphology it is very similar to $A$. adustus Baehr, but differs by being generally smaller in size, always reddish in colour, with much finer and sparser punctuation of the pronotum and elytra, and the wider female stylomere.

The new specimens from near Meekatharra and those from the Pilbara closely match the holotype in shape and structure, whereas the single female specimen from near Peak Charles is only provisionally included in this species, because the punctation of the elytra is perceptibly denser and coarser. Males from this southern locality are required for final assessment of their taxonomic status. Two of the new specimens are males, allowing the male genitalia of this species to be described for the first time.

\section{Adelotopus adustus Baehr, 1997}

Figure 20

Adelotopus adustus Baehr, 1997: 229; Baehr, 2002: 117.

\section{New material examined}

Australia: Western Australia: 2 o, 2 , site WA06/49, Murchison River, $5 \mathrm{~km}$ E. of Galena Bridge, 27.83590 $\mathrm{S}, 114.71719$ E, 125 m, 18 January 2006, M. Baehr (CBM); 3 \&, site WA06/35, Lake Koorkoordine, $3 \mathrm{~km} \mathrm{~N}$. of Southern Cross, 31.18233 ${ }^{\circ}$, 119.30811 E, $352 \mathrm{~m}, 7$ January 2006, M. Baehr (CBM); 56 of , site WA06/68, $1 \mathrm{~km} \mathrm{W.} \mathrm{of}$ Cunderdin, $31.65293^{\circ} \mathrm{S}, 117.21513 \mathrm{E}, 202 \mathrm{~m}, 23$ January 2006, M. Baehr (CBM, WAM 67937-41); 1 $q$, site WA06/85, $30 \mathrm{~km}$ NNW. of Leonora, 28.61799 $\mathrm{S}, 121.19967 \mathrm{E}, 441 \mathrm{~m}, 30$ January 2006, M. Baehr (CBM); 1 , site WA06/157, $90 \mathrm{~km} \mathrm{W.} \mathrm{of}$ Sandstone, $28.05690^{\circ} \mathrm{S}, 118.44989 \mathrm{E}, 444 \mathrm{~m}, 27$ February 2006, M. Baehr (CBM); 1 q, site WA06/ $160,25 \mathrm{~km} \mathrm{~N}$. of Mt. Keith, 27.09955' S, 120.44376 E, $541 \mathrm{~m}, 1$ March 2006, M. Baehr (CBM); 2 , site WA06/161, $5 \mathrm{~km} \mathrm{~N}$. of Lake Miranda, $27.59482^{\circ} \mathrm{S}$, 120.53724 E, 480 m, 1 March 2006, M. Baehr (CBM).

\section{Remarks}

This species has been previously recorded from a few old specimens from Western Australia and north-western Victoria, mostly lacking precise localities (Baehr 1997). The additional records from the latter area cited by Baehr (2002), however, I now believe to belong rather to $A$. laticollis Baehr than to
A. adustus. Hence, the occurrence of this species in Victoria is still doubtful.

The new material suggests a wide distribution of this species in central and southern inland Western Australia. Moreover, some external features (colour, size, degree of punctuation of the surface) seem to be quite variable, since the specimens from Murchison River (site WA06/49), Lake Koorkoordine (site WA06/35), and most specimens from Cunderdin (site WA06/68) are dark piceous or even completely black, whereas those from more inland/northern localities are rather reddish. The specimens from Murchison River which are completely black are more densely and coarsely punctate on the pronotum and elytra than the other specimens. However, the male and female genitalia of dissected specimens from all localities are similar to those figured by Baehr (1997) and do not show any major differences. Therefore, it seems that all specimens belong to a single widespread and quite variable species.

The new specimens were either collected from under bark of River Red Gum (Eucalyptus camaldulensis), Salmon Gum (E. salmonophloia), and Redwood (E. transcontinentalis), or they were fogged from the rough-barked trunks of Mulga Acacias (Acacia aneura) and of an unidentified extremely rough-barked Acacia.

\section{Adelotopus minutus sp. nov.}

$$
\text { Figures 10, } 20
$$

\section{Material examined}

\section{Holotype}

Australia: Western Australia: ơ, site WA06/13, 3 $\mathrm{km}$ E. of Ravensthorpe, $33.60543^{\circ} \mathrm{S}, 119.87906^{\circ} \mathrm{E}, 166$ m, 2 January 2006, M. Baehr (WAM 67942).

\section{Etymology}

The name refers to the small size of this species in comparison to the most similar species.

\section{Diagnosis}

Small, short and wide, reddish species of the rubiginosus species-group of Baehr (1997), characterized by presence of traces of microreticulation on frons and by striolate aedeagus; distinguished from both most similar species Adelotopus adustus Baehr and $A$. houstoni Baehr by the smaller size, narrower aedeagus bearing a longer and narrower, at left side (seen from below) not convex apical part and more acute apex, and much wider genital ring. Further distinguished from $A$. adustus by its reddish colouration and non-triangular right paramere; and from $A$. houstoni by the decidedly denser and coarser punctuation on the pronotum and elytra. 


\section{Description}

Measurements: length: $3.9 \mathrm{~mm}$; width: $1.75 \mathrm{~mm}$. Ratios. Width/length of pronotum: 1.74 ; width base/apex of pronotum: 1.44; width pronotum/ head: 1.52 ; length/width of elytra: 1.43 ; length elytra/pronotum: 2.50 .

Colour: upper and lower surface including mouth parts, antennae, and legs reddish.

Head: rather short, fairly wide, rather depressed. Anterior border gently convex, lateral angle rounded, laterally faintly projecting, lateral borders slightly narrowed behind eyes. Clypeal suture only at base distinct, in middle widely interrupted. Labrum rather wide and short, moderately overlapped by the clypeus, apex moderately concave. Antennal groove laterally sharply bordered, latero-posteriorly with slightly convex area. Mental tooth triangular, short, apex acute. Wings of mentum wide, laterally rounded, apex obtuse. Glossa fairly wide, tongue-like, apically convex, ventrally with distinct keel, at border with c. 10-12 elongate setae. Terminal palpomere of maxillary palpus moderately widened, fairly securiform. Terminal palpomere of labial palpus wide, securiform. Antenna moderately wide, $8^{\text {th }}-9^{\text {th }}$ antennomeres c. $1.5 \times$ as wide as long. Microreticulation fine, superficial, though visible, punctuation very fine, fairly dense. Surface with weak sulcus medially of eyes, impilose, rather glossy. Ventro-laterally of eyes with a row of short setae. Suborbital field punctate and shortly setose. Gula impilose.
Pronotum: rather wide, rather convex, base distinctly wider than apex, widest near base. Apical angles moderately produced, at apex acute, fairly oblique, well surpassing posterior border of eyes. Apex fairly excised, markedly convex in excision, feebly bordered. Sides gently convex, moderately oblique. Margins rather wide, moderately channelled, finely bordered. Basal angles widely rounded off. Base straight, rather distinctly bordered. Surface near base with shallow transverse impression. Microreticulation much reduced, highly superficial, punctuation moderately fine, rather dense, surface with fine, irregular strioles, impilose, highly glossy.

Elytra: rather wide and short, moderately convex, slightly depressed on disk, very gently narrowed from base. Apex wide, slightly oblique, truncature faintly convex, apical angles widely rounded off. Humeri rounded, basal margin slightly oblique, without setae behind shoulders. Marginal channel moderately wide, partly concealed. Basal border incomplete, attaining about middle of base. Lateral margin asetose. Series of umbilical pores consisting of 6 rather spaced pores behind shoulder. Setae fairly elongate. Striae including sutural stria absent. Microreticulation absent, punctuation moderately coarse, rather dense, surface impilose, very glossy.

Lower surface: prosternal process rather short, narrow, convex, apex very short, narrow, compressed, passing over in an almost right angle
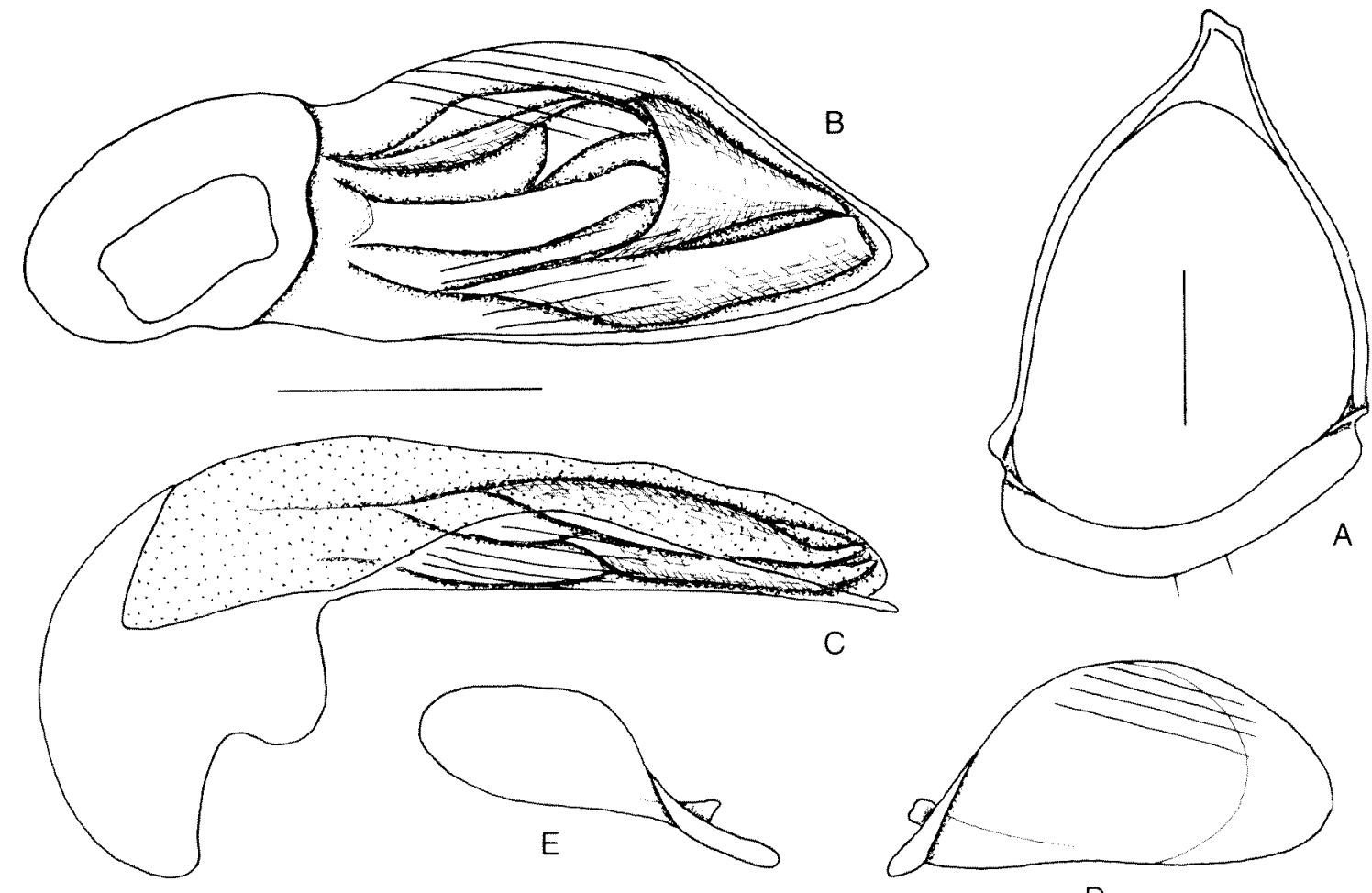

D

Figure 10 Adelotopus minutus sp. nov., details of male genitalia: A, male genital ring; B, lower surface of aedeagus; C, lateral view of aedeagus; D, left paramere; $\mathrm{E}$, right paramere. Scale lines: $0.25 \mathrm{~mm}$. 
from ventral surface, shortly setose. Metepisternum elongate, c. $1.8 \mathrm{x}$ as long as wide, in posterior third not hollowed. Abdominal sterna with 1 elongate seta each side. Lower surface rather densely punctate and shortly pilose.

Legs: elongate, $1^{\text {st }}$ tarsomere of protarsus slightly longer than wide, tibial groove of profemur moderately deep, anterior plate overlapping the groove for about apical third, posterior border of groove sharp. Femur wide. Metatibia elongate, c. 6 $x$ as long as wide, $1^{\text {st }}$ tarsomere of metatarsus $2.4 x$ as long as wide.

Male genitalia (Figures 10A-E): genital ring very wide, convex, asymmetrical, with moderately elongate apex, with asymmetrical, very short, excised base. Sternum VII very wide, apically evenly convex, with moderately deep excision, base faintly bisinuate, in middle convex, basal angles obtusely rounded, lateral parts elongate. Aedeagus short, depressed, in middle moderately widened, asymmetrical, right side almost straight. Basal part rather long, markedly bent. Lower surface almost straight, markedly striped. Lateral border narrow. Apical narrowed part elongate, apex remarkably acute, asymmetrical. Orifice very elongate, internal sac complex, with a large oblique fold near apex. Both parameres rather elongate, at apex widely rounded off, right paramere fairly parallel, left paramere considerably larger and more triangularconvex towards apex.

Female genitalia: unknown.

Variation: unknown.

Vivipary: not confirmed in the examined material.

\section{Distribution}

This species is known only from the type locality in southern-most Western Australia (Figure 20).

\section{Habits}

Largely unknown. Holotype collected from under bark of Salmon Gum (Eucalyptus salmonophloia).

\section{Remarks}

According to the shape and structure of the male aedeagus, this species is most similar to $A$. adustus Baehr and A. houstoni Baehr.

\section{Adelotopus paroensis Castelnau, 1867 Figure 19}

Adelotopus paroensis Castelnau, 1867: 32; Baehr, 1997: 312; Baehr, 2002: 124.

\section{New material examined}

Australia: Western Australia: $1 \delta$, site WA06/46, $10 \mathrm{~km}$ WNW. of Northampton, $28.31817^{\circ} \mathrm{S}$, $114.54298^{\circ} \mathrm{E}, 72 \mathrm{~m}, 11$ January $2006, \mathrm{M}$. Baehr (CBM).

\section{Remarks}

This very widespread and common species from the drier areas of southern and eastern Australia was not previously reliably recorded from Western Australia, from where only an unspecified old series were previously available. The new specimen from Northampton is the first reliable Western Australian record. Apparently, A. paroensis is rare in Western Australia, since no other specimens could be collected in spite of ample hand collecting and fogging of tree trunks, and no specimens were found in any of Western Australian collections examined by the author. The new specimen was sampled from under bark of a River Red Gum (Eucalyptus camaldulensis).

\section{Genus Cainogenion Notman, 1925}

Cainogenion Notman, 1925: 11, 30; Baehr, 1997: 328.

\section{Type species}

Adelotopus ipsoides Newman, 1837 by original designation.

\section{Remarks}

The exclusively Australian genus Cainogenion at present includes 13 taxa of quite similar shape and structure. According to certain highly apomorphic features of legs and female stylomeres the genus forms a group with Adelotopus and Paussotropus, but certainly is nearer related to the latter genus (Baehr 1994a). Species of Cainogenion can be found in most parts of Australia, but apparently they are much rarer than those of Adelotopus. They live under bark or in deep cracks in the bark of various trees and rarely they are also attracted to the light.

\section{Cainogenion ipsoides occidentale Baehr, 1997 Figure 20}

Cainogenion inpsoides occidentale Baehr, 1997: 344.

\section{New material examined}

Australia: Western Australia: 1 q, Little Darkin Swamp, 32.04S, 116.30 E, 25 October 1987, J. M. Waldock (WAM 67943).

\section{Remarks}

This subspecies is restricted to south-western Australia, whilst the other is found in south-eastern Australia (Baehr 1997). To date, only a few specimens have been recorded, and only one bears a precise locality (Pemberton).

\section{Genus Paussotropus Waterhouse, 1877}

Paussotropus Waterhouse, 1877: 3; Baehr, 1997: 370. 

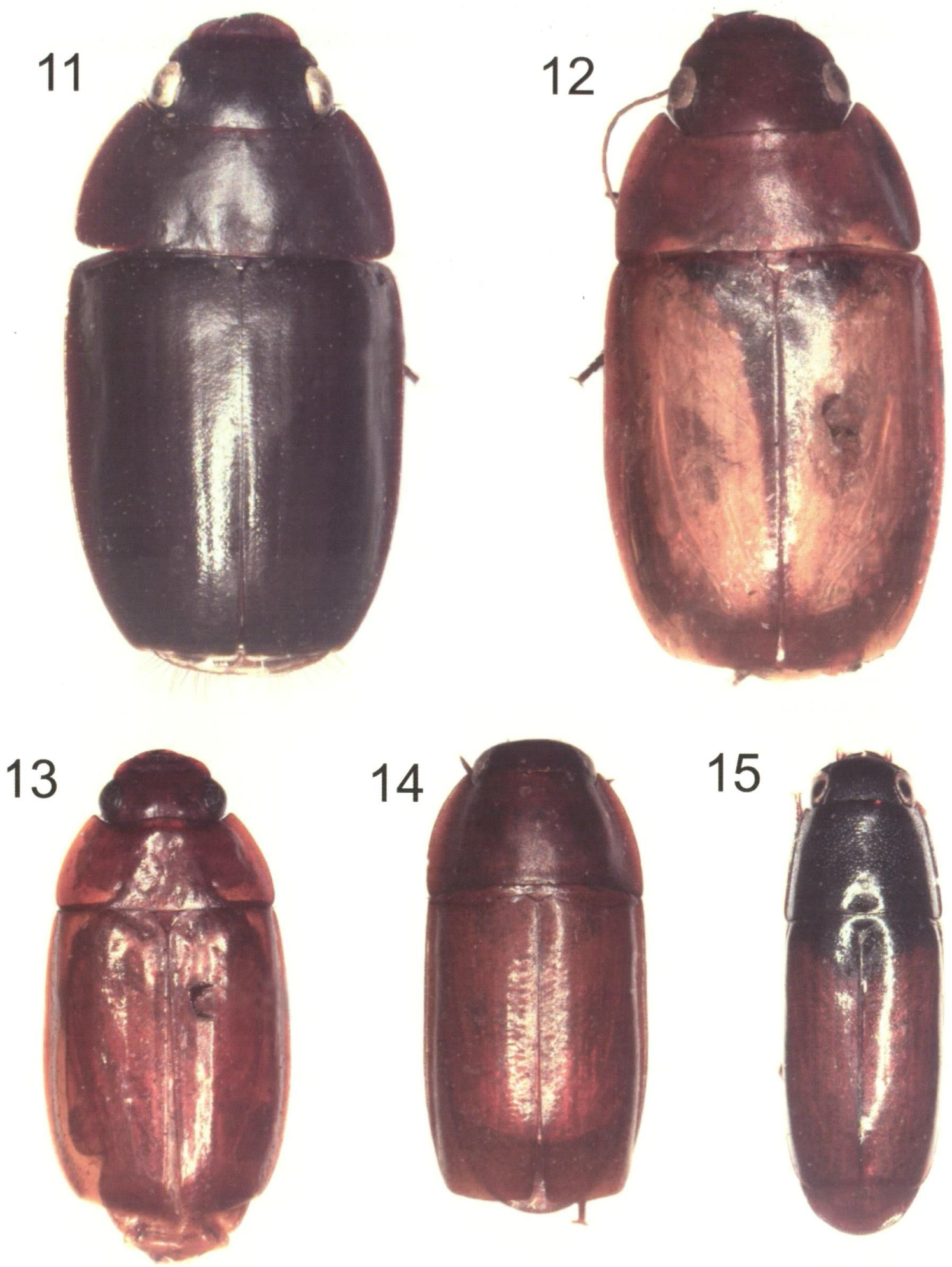

Figures 11-15 Habitus. 11, Sphallomorpha permutata sp. nov.; 12, S. flavorufa sp. nov.; 13, S. clypeosetosa sp. nov.; 14, Adelotopus pilbarae sp. nov.; 15, A. basalis sp. nov.

\section{Type species}

Paussotropus parallelus Waterhouse, 1877 (junior synonym of Adelotopus cylindricus Chaudoir, 1862), by monotypy.

\section{Remarks}

The monotypic genus Paussotropus in many respects exhibits the utmost morphological development within Pseudomorphinae, in body shape and structure, shape of legs, antennae, female genitalia, and also of larvae (Baehr 1997). The single species Paussotropus cylindricus even is commonly mistaken for a cucujid or colydiid, because its shape and structure is much derived from that of a 


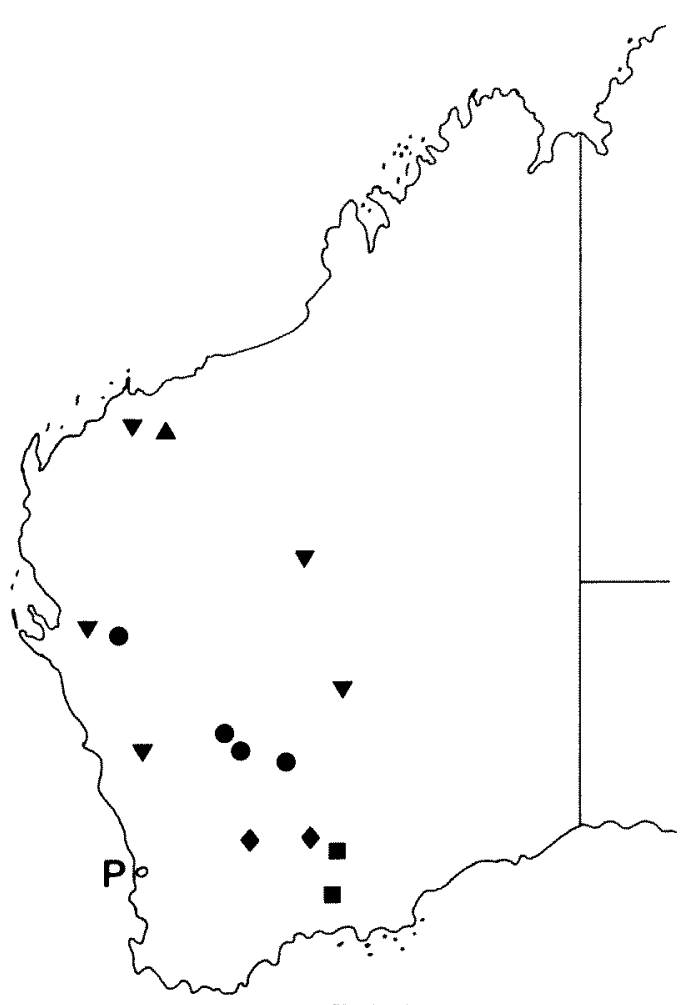

Figure 16 Recorded distribution in Western Australia: Sphallomorpha fallax (Westwood) (Ш); $S$. parinterioris sp. nov. (O); S. polysetosa Baehr $(\bullet)$; S. maculata (Newman) (A); S. uniformis Baehr $(\boldsymbol{\nabla})$. $(\mathrm{P}=$ Perth; scale line: $500 \mathrm{~km}$ ).

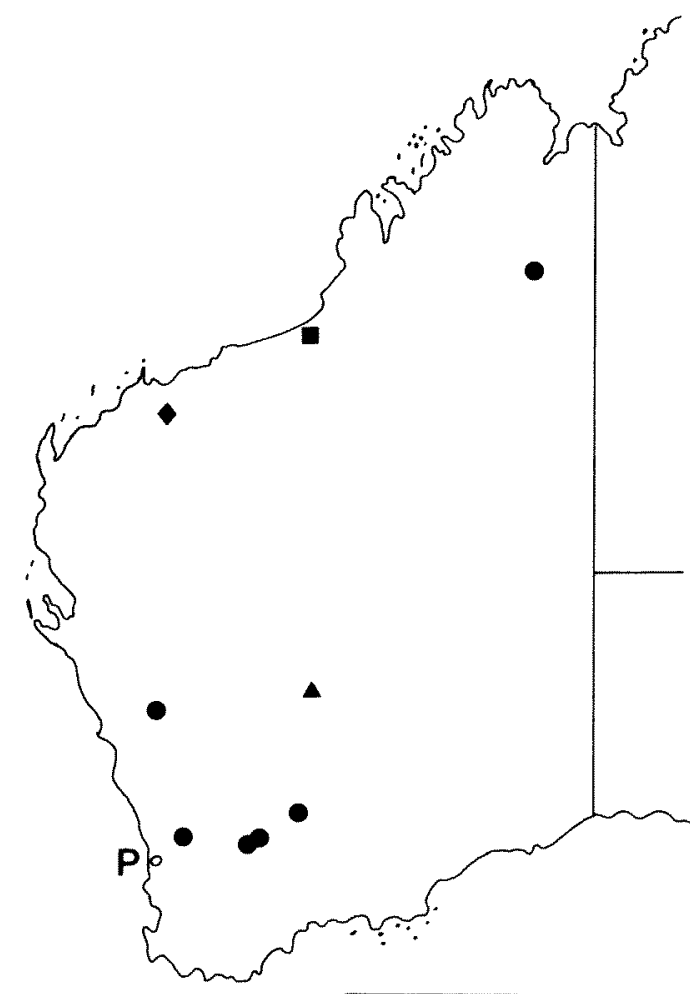

Figure 18 Recorded distribution in Western Australia: Sphallomorpha flavopicea Baehr (O); $S$. clypeosetosa sp. nov. (回); Adelotopus coriaceus Baehr ( $\bullet$ ); A. basalis sp. nov. (A). $(\mathrm{P}=$ Perth; scale line: $500 \mathrm{~km})$.

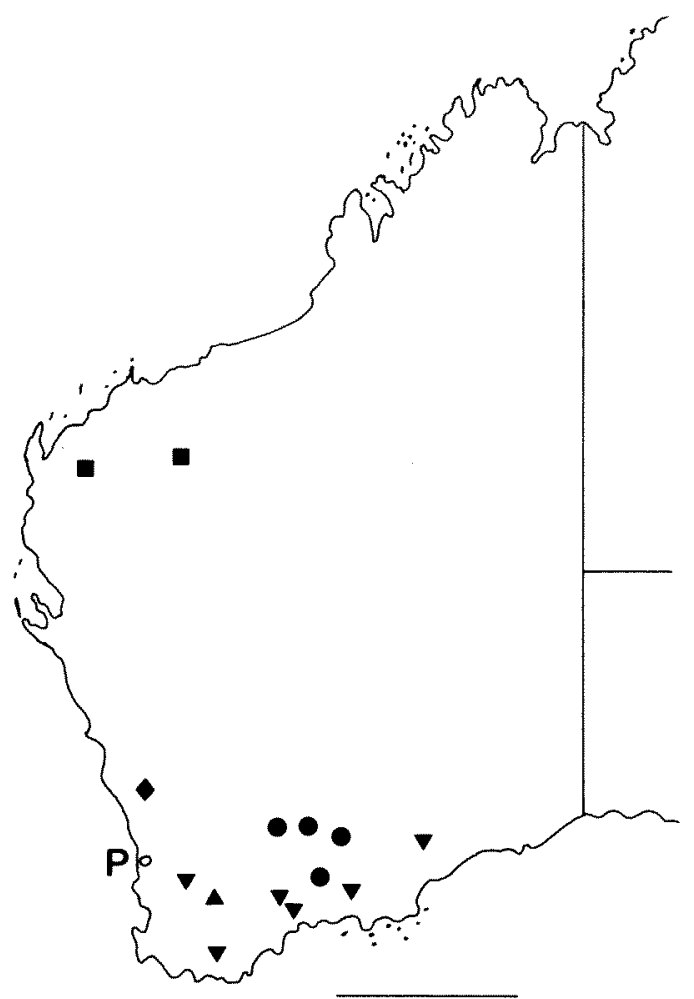

Figure 17 Recorded distribution in Western Australia: Sphallomorpha permutata sp. nov. (O); $S$. szitoi sp. nov. ( ) ; S. flavorufa sp. nov. (A);

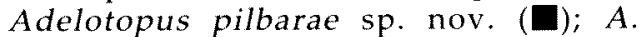
puncticollis angustemaculatus Baehr $(\boldsymbol{\nabla})$. ( $(\mathrm{P}$ $=$ Perth; scale line: 500 km).

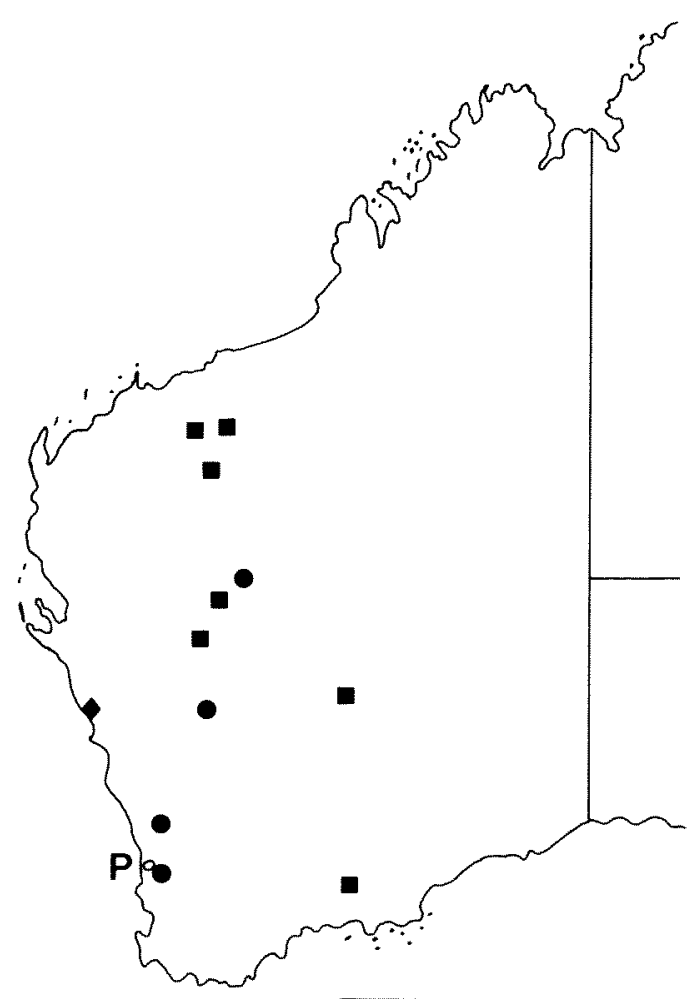

Figure 19 Recorded distribution in Western Australia: Adelotopus rubiginosus Newman (O); $A$. houstoni Baehr $(\mathbf{G})$; A. paroensis Castelnau $(\checkmark) .(\mathrm{P}=$ Perth; scale line: $500 \mathrm{~km})$. 
"normal" carabid. The unique species is distributed through large parts of Australia, but is rarely sampled and mostly at light. Hence we do not even know where and how it lives.

\section{Paussotropus cylindricus (Chaudoir, 1862)}

Figure 20

Cainogenion cylindricum Chaudoir, 1862: 490.

Paussotropus cylindricus, Baehr, 1997: 370; Baehr, 2002: 124.

\section{New material examined}

Australia: Western Australia: 1 \& CALM Pilbara Survey, DRW09, $7 \mathrm{~km}$ SE Marda Pool, 21 41'11.7"S, $116^{\circ} 12^{\prime} 24.7^{\prime \prime} \mathrm{E}, 25 . \mathrm{IX}-26$ November 2003 (DEC).

\section{Remarks}

This is a rare though widespread species that is recorded from scattered localities throughout Australia, but almost all records (if specified at all) are from light samples, hence we do not yet know anything about habits and life history. The new specimen was sampled in a glycol pitfall trap which certainly is a rather untypical sampling method.

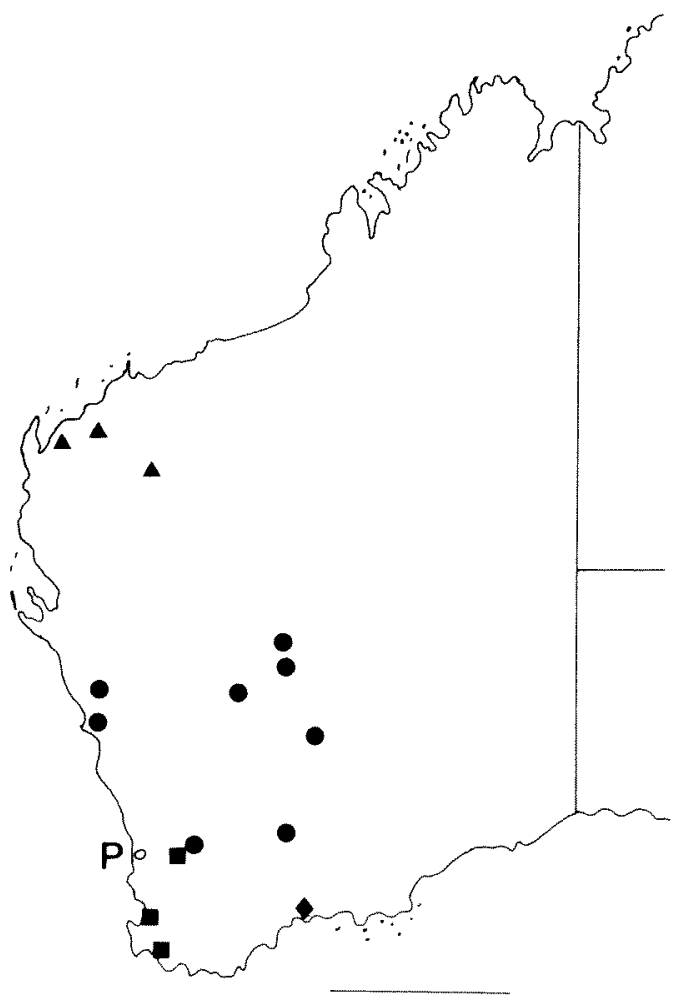

Figure 20 Recorded distribution in Western Australia: Adelotopus adustus Baehr (-); A. minutus sp. nov. ( $)$; Cainogenion ipsoides occidentalis Baehr ( Paussotropus cylindricus (Chaudoir) $(\mathbf{A}) .(\mathrm{P}=$ Perth; scale line: $500 \mathrm{~km}$ ).

\section{Recognition}

To insert the new species in the general keys (Baehr 1992, 1997, 2002), these must be altered as mentioned below (figures of these revisions are inserted as B92 Figure and B97 figure).

\section{Sphallomorpha parinterioris sp. nov.}

Using the key to species in Baehr (1992) either couplet 22 is reached (for males) if the preorbital seta is absent, or couplet 29 if it is present. For females either couplet 39 is reached if the preorbital seta is present, or couplet 42 if it is present. These couplets must be altered as follows:

22. Preorbital seta absent ............................... 22a

Preorbital seta present 24

22a. Pronotum with 2 or more posterior marginal setae; either apex of aedeagus acute, hookshaped and suddenly bent down (B92 Figures $38 \mathrm{i}, \mathrm{k}$ ), or more gently curved down, in this case sternum VII deeply excised (B92 Figures 51i, k, g) (northeastern NSW, eastern QLD) ................... 23

Pronotum with a single posterior marginal seta; apex of aedeagus obtuse, barely bent down (Figure 1E, F) (central WA)

S. parinterioris $\mathrm{sp}$. nov.

29. Aedeagus with wide, obtuse apex; left paramere elongate, narrow, sinuate, excision of sternum VII shallow and very wide, somewhat rectangular (Figures 1B, E; B92 Figures $52 \mathrm{~g}, \mathrm{k}$ ) (central NT, central WA). $29 \mathrm{a}$

Aedeagus with attenuate, rather narrow, convex apex; left paramere shorter, wide, not sinuate; excision of sternum VII evenly concave (B92 Figures $47 \mathrm{~g}, \mathrm{k}, 48 \mathrm{~g}$, $k, 50 g, k$ ) (eastern AUS, northern NT) ... 30

29a. Apex of aedeagus sharply bent down (B92 Figure 52i) (central NT)

S. interioris Baehr

Apex of aedeagus barely bent down (Figure 1E) (central WA) .. S. parinterioris sp. nov.

39. Preorbital seta absent ..............................39a

Preorbital seta present 40

39a. Pronotum with 2-3 posterior marginal setae; sternum VII elongate, apex of stylomere 2 moderately elongate, rather obtuse (B92 Figures 5ln, o) (northern Qld) S. striatopunctata Baehr

Pronotum with a single posterior marginal seta only; sternum VII shorter, stylomere 2 elongate and acute (Figures 1C, I; B92 Figures 52n, o) (central WA) S. parinterioris $\mathrm{sp}$. nov. 
42. Punctuation of striae and intervals finer; either sternum VII markedly elongate (B92 Figure 47n), or elytra shorter, ratio l/ w $<1.20$ (eastern QLD, northern NT, northern WA) 43

Punctuation of striae and intervals coarse; sternum VII short (Figure 1C; B92 Figure $52 \mathrm{n}$ ), and elytra always elongate, ratio $\mathrm{l} / \mathrm{W}$ $>1.20$ (central NT, central WA) $42 a$

42a. Stylomere 2 with short apex (B92 Figure 52p) (central NT) S. interioris Baehr

Stylomere 2 with elongate apex (Figure 1I; B92 Figure 52o) (central WA)

S. parinterioris sp. nov.

\section{Sphallomorpha permutata sp. nov.}

Using the key to species in Baehr (1992) either couplet 85 . is reached (for males), or couplet 109 is reached for females. These couplets must be altered as follows:

85. Aedeagus rather short, slightly sinuate, apex wide, obtusely rounded, orifice short; excision of sternum VII wide, rather shallow, sternum with 5-8 setae, setae usually shorter (B92 Figures 78g, i, k, 79g, $\mathrm{i}, \mathrm{k}$ )

86

Aedeagus varied, but when short, then not sinuate, apex less wide, rather acute, orifice elongate; excision of sternum VII usually deep, sternum with 12-20 very elongate setae (Figure 2B; B92 Figures 92g, i, $k, 94 \mathrm{~g}, \mathrm{i}, \mathrm{k}$ ) 87

87. Labrum 6-setose; punctuation of elytra coarse, though rather sparse and irregular; aedeagus see B92 Figures 94i,k; right paramere with shorter apex (B92 Figure 941) (north-western VIC) ... S. dixoni Baehr

Labrum 4-setose; punctuation of elytra less coarse, though dense and regular; aedeagus see Figure 2E, F; B92 Figures 92i, $\mathrm{k}$; right paramere with longer apex (Figure 2G; B92 Figure 921) (NSW, eastern QLD, south-western WA) $87 a$

87a. Sternum VII with 12-16 setae (B92 Figure 92g); aedeagus symmetrical, dark area at left side more extended (B92 Figure 92i, $k$ ) (eastern NSW, eastern QLD) S. polita (Macleay)

Sternum VII with 17-18 setae (Figure 2B); aedeagus slightly asymmetrical, dark area at left side less extended (Figure 2E, F) (south-eastern WA) S. permutata sp. nov.

109. Sternum VII slightly shorter, with 14-20 setae (Figure 2C; B92 Figure 92n); punctuation of elytra slightly less dense (B92 Figure 401). 109 a

Sternum VII slightly longer, with 11-14 setae (B92 Figure 91n); punctuation of elytra slightly denser (B92 Figure 400) (northern QLD, northern NT, northern WA) S. laevis (Castelnau)

109a. Sternum VII with 14-17 setae (B92 Figure 92n) (northern NSW, eastern QLD) S. polita (Macleay)

Sternum VII with 19-20 setae (Figure 2C) (south-eastern WA) .. S. permutata sp. nov.

\section{Sphallomorpha szitoi sp. nov.}

Using the key to species in Baehr (1992) couplet 106 is reached (for the only known female). This couplet must be altered as follows:

106. Sternum VII with only 2 setae (Figure 3A); elytra elongate and rather parallel, ratio $\mathrm{l} /$ w c. 1.25 (south-western WA)

S. szitoi sp. nov.

Sternum VII with $>9$ setae (B92 Figures 79n, $91 n, 92 n, 93 n, 97 n) ;$ elytra shorter and laterally more convex, ratio $\mathrm{l} / \mathrm{w}<1.20$ (eastern AUS, northern QLD, northern NT, northern WA) $106 a$

$106 \mathrm{a}=106$ of key

\section{Sphallomorpha flavopicea Baehr}

Using the key to species in Baehr (1992) couplet 165 is reached. This couplet must be altered as follows:

165. Small species (<7 mm); preorbital seta absent; antenna short (median segments c. $1.4 \mathrm{x}$ as long as wide) (B92 Figure 120e); des and ves of stylomere 2 close to apex, base not concealed (B92 Figure 120o); elytra with ill defined, large, heart-shape spot and with very ill delimited lateral margin (B92 Figure 283); male unknown (southwestern WA) S. wilgae Baehr

Usually larger species $(>7.3 \mathrm{~mm})$, when small, then with sutural stripe; preorbital seta present; antenna longer (median segments $>2 \times$ as long as wide); des and ves of stylomere 2 perceptibly removed from apex, base concealed or not (B92 Figures 161 o, 168o, 179o); elytra with less ill defined, variously patterned 166

166. Rather small $(6.8-7.5 \mathrm{~mm})$, characteristically light piceous-ochraceous coloured species with very wide, light borders to pronotum and elytra and a wide, triangularly attenuate discal stripe (B92 Figure 312); 
apex of wings of mentum acute, gular sutures obtusely angulate (B92 Figure 160); aedeagus elongate, with acute and slightly upturned apex, on left side conspicuously knobbed, left paramere remarkably elongate (Figures $4 \mathrm{~B}-\mathrm{E}$ ); base of stylomere 2 not concealed, two widely spaced ves present (B92 Figure 1610) (WA) S. flavopicea, sp. nov.

Usually larger $(>7.3 \mathrm{~mm})$ species with different pattern and colouration; apex of wings of mentum obtuse, gular sutures almost evenly convex (B92 Figures 167, $169,171,178,180$ ); base of stylomere 2 partly concealed (unknown in one species), ves usually less spaced (B92 Figures $1700,1720,1790,1810-1920) .167$

\section{Sphallomorpha flavorufa sp. nov.}

Using the key to species in Baehr (1992) couplet 133 is reached (for the only known male). This couplet must be altered as follows:

133. Head and pronotum reddish, elytra almost completely yellow, leaving only the suture dark which widens towards base but leaves scutellar area reddish, and margin in apical half slightly darker (Figure 12) (south-western WA) S. flavorufa sp. nov.

Head and pronotum either reddish or dark, but elytra always with much less extended, definite discal patch or stripe (B92 Figures 336-341). $133 a$

$133 \mathrm{a}=133$ of $\mathrm{key}$.

\section{clypeosetosa species-group}

Using the key to species-groups in Baehr (1992) couplet 19 is reached. This couplet must be altered as follows:

19. Clypeus with more than the usual 2 setae (Figure 6A); all fixed setae on head and sternum VII conspicuous and pit-shaped (Figures 6A, B, D, E)

S. clypeosetosa species-group

Clypeus only with the usual 2 setae; fixed setae on head and sternum VII not pitshaped $19 \mathrm{a}$

$19 \mathrm{a}=19$ of $\mathrm{key}$.

\section{Sphallomorpha dypeosetosa sp. nov.}

Using the key to species in Baehr (1992) couplet 114 is reached. This couplet must be altered as follows:
114. Clypeus with more than the usual 2 setae (Figure 6A); all fixed setae on head and sternum VII conspicuous and pit-shaped (Figures 6A, B, D, E); colour uniformly light reddish ....... S. clypeosetosa sp. nov.

Clypeus only with the usual 2 setae; fixed setae on head and sternum VII not pitshaped; light brown, piceous, or black species .......................................... 114a

$114 a=114$ of key.

\section{Adelotopus pilbaraesp. nov.}

Using the key to species in Baehr (1997) couplet 96 is reached. This couplet must be altered as follows:

96. Large species, length 6.5-6.9 mm, body wide, markedly depressed, colour light reddish, with very wide pronotum with wide base, ratios $w / 1$ of pronotum $1.84-1.88$, base/ apex $>1.74$; apical angles of pronotum remarkably elongate, basal angles almost rectangular, markedly projecting posteriorly, base laterally distinctly concave (B97 Figure 113); aedeagus see B97 Figures $112 \mathrm{~g}$, h; stylomere markedly widened in middle (B97 Figure 1121) (northern WA) ............ A. rufescens Baehr

Generally smaller species, length $<6.55 \mathrm{~mm}$, body narrower, less depressed, colour either yellow, or darker reddish or reddish-piceous, with narrower pronotum and narrower base, ratio $w / 1$ of pronotum $<1.83$, base/apex <1.64; apical angles of pronotum less elongate, basal angles rectangular or obtuse, more or less projecting posteriorly, base laterally less distinctly concave (Figure 14; B97 Figures 114, 298, 302-307); aedeagus see Figure 7B-E; B97 Figures $109 \mathrm{~g}-\mathrm{k}, 115 \mathrm{~g}-\mathrm{k}, 119 \mathrm{~g}-\mathrm{k}$ 97

97. Colour yellow; lateral margin of pronotum much incurved towards base, basal angle obtuse (B97 Figure 114); elytra short, ratio I/w 1.3; aedeagus see B97 Figures 115g-k (northern NT) ................. A. flavus Baehr

Colour reddish to piceous; lateral margin of pronotum less incurved towards base, base rectangular or obtuse, in latter case colour piceous with lighter margins (Figure 14; B97 Figures 303--307); elytra longer, ratio $\mathrm{I} / \mathrm{W}>1.38$; aedeagus (see Figure 7B-E; B97 Figures $109 \mathrm{~g}-\mathrm{k}, 116 \mathrm{~g}-\mathrm{k}$,

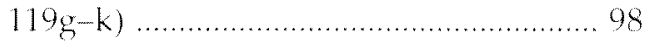

98. Either pronotum wide, ratio $w / 1>1.77$ or elytra narrow and elongate, ratio $1 / w>$ 1.62 (Western Australia) ....................... 99 
Ratio $w / 1$ of pronotum $<1.74$ and ratio $1 / w$ of elytra $<1.55$ (Eastern Australia) 100

99. Body longer, parallel, with narrower pronotum, ratios $w / 1$ of pronotum $<1.72,1 /$ $\mathrm{w}$ of elytra $>1.62$; aedeagus longer and narrower, with longer apex (B97 Figure $109 \mathrm{~g}$ ) (northern WA north of Great Sandy Desert) A. elongatulus Macleay

Body shorter, wider, with wider pronotum, ratios $w / 1$ of pronotum $>1.77,1 / w$ of elytra $<1.48$; aedeagus shorter and wider, with shorter apex (Figure 7B; B97 Figure 116g) (WA south of Great Sandy Desert) ..... 99a

99a. Colour piceous, with lighter margins of pronotum and elytra; basal angles of pronotum produced over base, base straight; aedeagus with widely rounded apex (B97 Figure 116g); female stylomere unknown (southern WA). A. piceus Baehr

Colour reddish, without distinctly lighter margins of pronotum and elytra; basal angles of pronotum produced over base, base laterally sinuate; aedeagus with narrowly rounded to angulate apex (Figure 7B); female stylomere parallel (Figure 7F) (southern WA)

A. pilbarae sp. nov.

\section{Adelotopus basalis sp. nov.}

Using the key to species in Baehr (1997) couplet 20 is reached. This couplet must be altered as follows:

20. Only base of elytra narrowly black, apical $4 / 5$ red. Body narrow, very elongate, cylindrical (eastern Qld, northern NT, northern WA) A. linearis Macleay

Either base of elytra more extensively black, usually only apex more or less widely red or base narrowly black, but black colour visible laterally in basal half . .21

21. More than apical half of elytra reddish and reddish area anteriorly remarkably convex and prolonged along suture (Figure 15; B97 Figures 50, 356, 357) and head and pronotum densely and coarsely punctuate; apex of aedeagus remarkably acute, dentiform (Figure 8b; B97 Figures $168 \mathrm{~g}, 169 \mathrm{~g})$; lateral plate of female stylomere very short (Figure 8F; B97 Figures 1681, 1691)

Either only apex of elytra reddish or reddish area anteriorly straight or concave or head and pronotum not coarsely punctate. Apex of aedeagus never dentiform. Lateral plate of female stylomeres usually less short....
22. Red colour occupying almost the whole of the elytra, base only narrowly black and lateral black margin narrow, inconspicuous and developed only in basal half (Figure 15); size smaller, length $<4.6 \mathrm{~mm}$; apex of aedeagus even more acute (Figure 8B) (central WA)

A. basalis sp. nov.

Red colour occupying at most the posterior two thirds of the elytra, base more widely black and lateral black margin wider, conspicuous and complete (B97 Figure 357); size larger, length $>4.8 \mathrm{~mm}$; apex of aedeagus slightly less acute (B97 figs168g, $169 \mathrm{~g}$ ) (south-western WA, SA, VIC, southwestern NSW) $22 \mathrm{a}$

$22 \mathrm{a}=22$. of $\mathrm{key}$

\section{Adelotopus houstoni Baehr and Adelotopus minutus sp. nov.}

Using the most recent key to the species of the rubiginosus species-group in Baehr (2002) for males of $A$. houstoni and $A$. minutus couplet 115 is reached. This couplet must be altered as follows:

115. Small species, length $<4.0 \mathrm{~mm}$; aedeagus with triangular, elongate and remarkably acute apex and genital ring very wide (Figures 10A,B) and colour reddish and pronotum and elytra densely and rather coarsely punctuate; female unknown (southern WA) ............ A. minutus sp. nov.

Larger species, length $>4.5 \mathrm{~mm}$, usually considerably larger; aedeagus with less triangular and acute apex, commonly genital ring narrower (Figures 9A,B; B97 Figures 177f,g-180f,g); colour reddish to piceous, or even black; punctuation of pronotum and elytra various, but when body length $<5.0 \mathrm{~mm}$, punctuation sparse

$115 a$

115a. Surface usually piceous to black, rarely reddish; punctuation of pronotum and elytra remarkably dense and coarse; pronotum with wide base, ratio base/apex 1.52-1.58; male genitalia see B97 Figures $179 \mathrm{f}-\mathrm{k}$ (southern half of WA)

A. adustus Baehr

Surface reddish; pronotum and elytra less densely and coarsely punctuate; pronotum with slightly narrower base, ratio base/apex $<1.48$; male genitalia variable (Figure 9A-E; B97 Figures 177 $\mathrm{f}-\mathrm{k}, 178 \mathrm{f}-\mathrm{k}, 180 \mathrm{f}-\mathrm{k})$ $115 b$

115b. Aedeagus very asymmetrical, more convex towards apex, laterally slightly impressed (B97 Figure 177g); left paramere large, 
somewhat triangular (B97 Figure 177k), punctuation on pronotum rather dense and fairly coarse, on elytra fine and sparse (SA, VIC, western NSW, central NT) ......... A. virgatus Baehr

Aedeagus less asymmetrical, less convex towards apex, laterally not impressed (Figure 9b; B97 Figures 178g, 180g); left paramere less triangular (Figure 9d; B97 Figures $178 \mathrm{k}, 180 \mathrm{k}$ ); punctuation either moderately dense and coarse or sparse and very fine on both, pronotum and elytra 116

116. Punctuation of surface very dense and fairly coarse (B97 Figure 519); aedeagus faintly concave towards apex (B97 Figure 180g); right paramere elongate, triangular, with acute apex (B97 Figure 180k); female unknown (NT) .... A. punctatissimus Baehr

Punctuation of surface sparse and fine (B97 Figure 517); aedeagus faintly convex towards apex (Figure 9B; B97 Figure $180 \mathrm{~g})$; right paramere either elongate with wide apex (Figure 9E), or short (B97 Figure 178k); female unknown

117. Large species, length $5.8 \mathrm{~mm}$; elytra shorter and wider, ratio $1 / \mathrm{w}$ 1.45; aedeagus narrower, right paramere short (B97 Figures $178 \mathrm{~g}, \mathrm{i}$ ) (central NT)

A. brittoni Baehr

Smaller species, length $<5.2 \mathrm{~mm}$; elytra longer and narrower, ratio $1 / \mathrm{w} \quad 1.49-1.55$; aedeagus wider, right paramere elongate (Figures 9B,E) (central and northern WA south of Great Sandy Desert)

A. houstoni Baehr

\section{Remarks}

The above records which do not pretend to represent the results of a systematic survey, clearly demonstrate the still extremely insufficient knowledge about species inventory and distribution of the arboricolous pseudomorphines in Western Australia. For further surveys, therefore the extended use of more sophisticated sampling methods is suggested, like collecting under loose bark with aid of an umbrella, fogging tree trunks, and even sampling by use of pitfall traps. Most surprising and also stimulating such surveys is the discovery of a striking and unique new species ( $S$. clypeosetosa) at the margin of Great Sandy Desert where arboricolous pseudomorphines are not likely supposed to exist.

Certainly the tropical part of Western Australia, north of Great Sandy Desert, is richer in species than the drier interior with its much more scattered tree growth, but even the dwarf, rather bush-like arid country tree vegetation of interior Western Australia, mainly composed of Mallee and Mulga, harbours quite a number of pseudomorphine species, even when the occurrence of species seems to be quite scattered. Therefore, apart from its taxonomic purpose, this paper should encourage any collectors of invertebrates to pay attention to these animals and to use more widely those sampling methods that are enumerated above.

\section{ACKNOWLEDGEMENTS}

I am greatly indebted to Miss Nadine Guthrie (Wanneroo), Mr Brian Hanich and Dr Terry Houston (Perth) and Dr Andras Szitó (Perth) for the kind loan of important material, and to the authorities of the Department of Conservation and Land Management of Western Australia (CALM) for issuing collecting permits for certain Western Australian National Parks and Conservation areas. Nadine is also thanked for her tireless efforts to sort out from the CALM Pilbara Survey material all those specimens relevant to $m y$ projects. I am further indebted to the authorities of the German Scientific Foundation (DFG) for support of this survey by a travel grant.

\section{REFERENCES}

Baehr, M. (1992). Revision of the Pseudomorphinae of the Australian Region 1. The previous genera Sphallomorpha Westwood and Silphomorpha Westwood. Taxonomy, phylogeny, zoogeography (Insecta, Coleoptera, Carabidae). Spixiana Supplement 18: 1-440.

Baehr, M. (1993a). New species and new records of the genus Sphallomorpha Westwood from Australia. Supplement to the "Revision of the Pseudomorphinae of the Australian Region 1." (Insecta, Coleoptera, Carabidae). Spixiana 16: 25-42.

Baehr, M. (1993b). A remarkable new species of the genus Sphallomorpha Westwood from Irian Java (New Guinea). 2. Supplement to the "Revision of the Pseudomorphinat of the Australian Region 1." (Insecta, Coleoptera, Carabidae). Spixiana 16: 207211

Baehr, M. (1994a). Phylogenetic relations and biogeography of the genera of Pseudomorphinae (Coleoptera, Carabidae). In: Desender, K., M Dufrene, M. Loreau, M. L. Luff and J.-P. Malfait (eds) Carabid Beetles: ecology and Evolution. Series Entomologica 51: 11-17. Kluwer, Dordrecht, Boston, London.

Baehr, M. (1994b). New species and new records of the genus Sphallomorpha Westwood from Australia and New Guinea. 3rd Supplement to the "Revision of the Pseudomorphinae of the Australian Region 1." (Insecta, Coleoptera, Carabidae). Spixiana 17: 215235.

Baehr, M. (1997). Revision of the Pseudomorphinac of the Australian Region 2. The genera Adelotopus 
Hope, Cainogenion Notman, Paussotropus Waterhouse, Pseudomorpha Kirby, and Cryptocephalomorpha Ritsema. Taxonomy, phylogeny, zoogeography (Insecta, Coleoptera, Carabidae). Spixiana Supplement 23: 1-510.

Baehr, M. (2002). New species and new records of Australian Pseudomorphinae. $4^{\text {th }}$ Supplement to the "Revision of the Pseudomorphinae of the Australian Region," (Insecta, Coleoptera, Carabidae). Spixiana 25: $101-129$

Baehr, M. (2004). A peculiar new species of the genus Sphallomorpha Westwood from New Guinea (Coleoptera: Carabidae: Pseudomorphinae). Koleopterologische Rundschau 74: 25-31.

Baehr, M. (2005). New species and new records of Australian Pseudomorphinae. $6^{\text {th }}$ Supplement to the "Revision of the Pseudomorphinae of the Australian Region." (Insecta, Coleoptera, Carabidae). Spixiana 28: $259-269$

Baehr, M. (2006). A new and another remarkable species of the genus Sphallomorpha Westwood from central Queensland, Australia (Coleoptera, Carabidae, Pseudomorphinae). Mitteilungen der Müncher Entomologischen Gesellschaft 96: 113-118.

Baehr, M. (2007). A new species of the genus Adelotopus Hope from northern Queensland, Australia (Insecta, Coleoptera, Carabidae, Pseudomorphinae). Spixiana 30: $25-28$.

Castelnau, F. L. de (1867). Notes on Australian Coleoptera. Royal Society of Victoria: 1-139.
Chaudoir, M. de (1862). Déscriptions, sommaires d'espèces nouvelles de Cicindélètes et de Carabiques de la collection de M. le Baron de Chaudoir. Revue et Magazin de Zoologie 14: 484-490.

Hope, F. W. (1834). Descriptions of some hitherto uncharacterized exotic Coleoptera, chiefly from New Holland. Transactions of the Entomological Society of London 1: 11-20.

Macleay, W. (1888). The insects of King's Sound and its vicinity. Proceedings of the Linnean Society of New South Wales 3: 443-480.

Newman, E. (1842). List of insects collected at Port Phillip, South Australia, by Edmund Thomas Higgins, Esq. Entomologist 23: 361-369.

Newman, E. (1856). Characters of three Pseudomorphina in the cabinet of Mr. Waterhouse. Transactions of the Entomological Society of London (ns) 8: 126-128.

Notman, H. (1925). A review of the beetle family Pseudomorphidae, and a suggestion for a rearrangement of the Adephaga, with descriptions of a new genus and new species. Proceedings of the United States National Museum 67 (no. 2586): 1-34.

Waterhouse, C. O. (1877). Descriptions of twenty new species of Coleoptera from various localities. Transactions of the Entomological Society of London 1877: 1-13.

Westwood, J. O. (1837). Illustrations of the relationships existing amongst natural objects, usually termed affinity and analogy, selected from the class of insects. Transactions of the Linnean Society of London 18: 209-221.

Manuscript accepted 23 May 2007. 